NBER WORKING PAPER SERIES

\title{
VIOLENCE AND THE FORMATION OF HOPELESSNESS AND PESSIMISTIC PROSPECTS OF UPWARD MOBILITY IN COLOMBIA
}

\author{
Andrés Moya \\ Michael Carter \\ Working Paper 20463 \\ http://www.nber.org/papers/w20463 \\ NATIONAL BUREAU OF ECONOMIC RESEARCH \\ 1050 Massachusetts Avenue \\ Cambridge, MA 02138 \\ September 2014, Revised February 2018
}

This paper previously circulated under the title "Violence and the Formation of Hopelessness and Pessimistic Prospects of Upward Mobility in Colombia." We thank Steve Boucher, Carlos Chiapa, Ghada Elabed, Hilary Hoynes, Miriam Golden, Guy Grossman, Rachid Laajaj, Evan Lieberman, Travis Lybbert, and Juan Fernando Vargas as well as the participants at the Northeast Development Conference at Harvard University, Households in Conflict Network Workshop at UC Berkeley, EGAP at Cape Town, and seminars at CIDE, UC Davis, University of Cape Town, and Universidad de los Andes for useful comments. Gabriela Paredes and María José Torres provided outstanding research assistance. This paper would have not been possible without the support of community leaders and local priests, and without the victims' willingness to participate and revisit their painful experiences of violence. The Pacific Rim Research Dissertation Grant, the Programa de Dinámicas Territoriales from RIMISP, and the Henry A. Jastro Award provided generous funding to collect the data, while the Harry Frank Guggenheim Foundation provided a dissertation fellowship to Moya. IRB Approval for the collection of human subjects data was awarded by the University of California, Davis. The usual disclaimers apply. The views expressed herein are those of the authors and do not necessarily reflect the views of the National Bureau of Economic Research.

NBER working papers are circulated for discussion and comment purposes. They have not been peer-reviewed or been subject to the review by the NBER Board of Directors that accompanies official NBER publications.

(C) 2014 by Andrés Moya and Michael Carter. All rights reserved. Short sections of text, not to exceed two paragraphs, may be quoted without explicit permission provided that full credit, including $(\odot$ notice, is given to the source. 
Violence and the Formation of Hopelessness and Pessimistic Prospects of Upward Mobility

in Colombia

Andrés Moya and Michael Carter

NBER Working Paper No. 20463

September 2014, Revised February 2018

JEL No. D03,D84,O12

\title{
ABSTRACT
}

We explore the impact of violence on perceived prospects of upward mobility. For a sample of victims of violence in Colombia, we bring together data on expected upward mobility, exposure to violence, and symptoms of psychological trauma. After controlling for material losses and current circumstances, we find that exposure to more severe violence leads victims' perceived prospects of upward mobility to become increasingly hopeless. The estimated impacts are large: victims exposed to more severe violence expect that the likelihood of being in extreme poverty in the long-run is more than two times as high than those exposed to less severe violence. Additional evidence indicates that depression and psychological trauma mediate this result, identifying a channel by which these pessimistic expectations can become self-confirming. Together, these findings suggest the existence of a psychological poverty trap and the need to rethink strategies to assist the economic recovery of the victims of violence.

\author{
Andrés Moya \\ Department of Economics \\ Universidad de los Andes \\ Calle 19A \# 1 - 37E \\ Bogotá, Colombia \\ a.moya@uniandes.edu.co \\ Michael Carter \\ Department of Agricultural and Resource Economics \\ University of California, Davis \\ One Shields Avenue \\ Davis, CA 95616 \\ and NBER \\ mrcarter@ucdavis.edu
}




\title{
VIOLENCE AND THE FORMATION OF HOPELESSNESS IN COLOMBIA
}

\author{
ANDRÉs Moya AND Michael R. CARTER*
}

We explore the impact of violence on perceived prospects of upward mobility. For a sample of victims of violence in Colombia, we bring together data on expected upward mobility, exposure to violence, and symptoms of psychological trauma. After controlling for material losses and current circumstances, we find that exposure to more severe violence leads victims' perceived prospects of upward mobility to become increasingly hopeless. The estimated impacts are large: victims exposed to more severe violence expect that the likelihood of being in extreme poverty in the long-run is more than two times as high than those exposed to less severe violence. Additional evidence indicates that depression and psychological trauma mediate this result, identifying a channel by which these pessimistic expectations can become self-confirming. Together, these findings suggest the existence of a psychological poverty trap and the need to rethink strategies to assist the economic recovery of the victims of violence. (JEL: D1; C9; O1; I1; I3)

Keywords: Violence; Psychological Trauma; Hope; Poverty; Colombia.

\footnotetext{
* This paper previously circulated under the title "Violence and the Formation of Hopelessness and Pessimistic Prospects of Upward Mobility in Colombia." Moya: Assistant Professor, Economics Department, Universidad de los Andes, Calle 19A \# 1-37E, Bogotá, Colombia, 111711, a.moya@uniandes.edu.co. Carter: Professor, Agricultural and Resource Economics, University of California, Davis, and NBER, mrcarter@ucdavis.edu. We thank Steve Boucher, Carlos Chiapa, Ghada Elabed, Hilary Hoynes, Miriam Golden, Guy Grossman, Rachid Laajaj, Evan Lieberman, Travis Lybbert, and Juan Fernando Vargas as well as the participants at the Northeast Development Conference at Harvard University, Households in Conflict Network Workshop at UC Berkeley, EGAP at Cape Town, and seminars at CIDE, UC Davis, University of Cape Town, and Universidad de los Andes for useful comments. Gabriela Paredes and María José Torres provided outstanding research assistance. This paper would have not been possible without the support of community leaders and local priests, and without the victims' willingness to participate and revisit their painful experiences of violence. The Pacific Rim Research Dissertation Grant, the Programa de Dinámicas Territoriales from RIMISP, and the Henry A. Jastro Award provided generous funding to collect the data, while the Harry Frank Guggenheim Foundation provided a dissertation fellowship to Moya. IRB Approval for the collection of human subjects data was awarded by the University of California, Davis. The usual disclaimers apply.
} 


\section{Introduction}

You know, doctor, it's been a few nights since I do not sleep, I have dreams where I see the heads of my neighbors. I see that they cry, that they supplicate, ask for mercy. I wake up crying. I start thinking about the farm, about my plants in the garden, about our chickens and cattle, and about our dogs that wanted to come with us, but we had to scare them away with rocks so that they would not follow us. I had never felt this way. I had never seen my husband so quiet; I had never seen him cry in silence. [...] I do not know what's going to happen with us, only that we have God and that our life will never be the same since we are now displaced. ${ }^{1}$

A victim of the tactics of terror that characterized the battle between warring factions in the Colombian countryside, the women quoted above poignantly testifies to both the loss of material assets, as well as the psychological damage created by her experience of violence and forced displacement. She seems hopeless regarding her ability to recover and progress.

We explore whether violence per se induces hopelessness and dampens perceived prospects of future upward mobility. Prior work has analyzed how asset losses stemming from violence, forced displacement, and other shocks thrust victims into chronic poverty (Carter, Little, Mogues, and Negatu, 2006; Ibáñez and Moya, 2010a, 2010b). In this paper, we explore whether the psychological consequences brought about by these traumatic events further damage the perceived prospects of future economic progress and recovery. In doing so, violence can create a behavioral poverty trap in its own right, akin to that which can occur with the loss of physical assets.

Our study is motivated by a burgeoning and interdisciplinary literature on the nature of hope and beliefs, and their relation to poverty dynamics. Work in this

\footnotetext{
${ }^{1}$ Doctors Without Borders (2010): Testimony of a woman in Florencia, Caquetá, who was displaced from her hometown after an armed group arrived to her village, killed and carved up some of her neighbors, and then made her bury them [Own translation].
} 
area is driven by the observation that economic behavior is ultimately driven by what individuals perceive is possible to achieve and what they aspire to achieve (Appadurai, 2004; Duflo, 2013; Lybbert and Wydick, 2017; Ray, 2006). For instance, perceptions of limited prospects of upward mobility may dampen goals and aspirations as a coping strategy-individuals may cease to desire and strive for things which do not seem possible to achieve. Diminished goals and aspirations, in turn, will inhibit the incentives to invest and improve current circumstances, to gather information about the pathways for progress, and even to modify such perceptions (Appadurai, 2004; Dalton, Ghosal, and Mani, 2011; Duflo, 2013; Ray, 2006). Hopelessness and a lack of aspirations can thus affect behavior and poverty dynamics.

We hypothesize that violence alters perceived prospects of upward mobility through a psychological mechanism as well as through the more discernible external constraints. ${ }^{2}$ Violence brings about external constraints related to the loss of material and productive assets and the descent into poverty, which will likely affect victims' perceptions of what is possible to achieve. In addition, the nature of the traumatic experiences of violence can also condition victims and induce depression and hopelessness-this is, perceptions that there are few pathways for recovery and progress (Sympson, 2000; Yehuda, 2002). The psychological damage associated with exposure to violence can thus reinforce the effect of external constraints and influence behavior. This is consistent with the recent work of Allousch (2017) and de Quidt and Haushoffer (forthcoming) who find that depression and other forms of psychological trauma diminish human capabilities and economic performance. Taken together, violence can lead to a vicious cycle of hopelessness, underachievement, and persistent poverty.

\footnotetext{
2 Lybbert and Wydick (forthcoming) lay out a conceptual framework for analyzing the relationship between external and internal constraints and how they determine poverty dynamics.
} 
To analyze whether victims' perceived prospects of upward mobility become increasingly hopeless, we sampled 344 victims of violence in Colombia. In section III, we describe our sampling strategy and data, which includes measures of the severity of household-level exposure to different violent events, symptoms of psychological trauma, and perceived prospects of upward mobility. For the latter, we first built upon the work of Krishna (2004, 2006, 2010) and Narayan, Pritchett, and Soumya (2009) and followed a "stages of progress" approach to construct a ladder of life appropriate for the study population. Then, we measured subjects' perceived prospects for future mobility building upon recent methods to elicit subjective probabilities (see Delavande, Gine, and McKenzie, 2011).

Our empirical strategy exploits the variation in the severity of violence, conditional on the individual's current position on the ladder of life and asset losses. Consistent with our hypothesis, we find that more severe violence dampens the perceived prospects of upward mobility. The estimated effects are substantial: an increase of a one standard deviation in the number of violent events raises the perceived probability of being at the bottom step of the ladder of life by 66 percent relative to the mean. Since our empirical strategy controls for the effect of current position on the ladder of life and material restrictions, these results point to the internal constraints that result from the experience of violence. In fact, we find that these diminished expectations of mobility are mediated by the severity of symptoms of depression. We describe these results in detail in section IV. Then, in section $\mathrm{V}$, we connect with more conventional analysis of poverty dynamics (e.g., Carter and May 2001), and use these results to estimate transition matrices that reveal the long-run perceived prospects for upward mobility. We observe that a one standard deviation in the number of violent events raises the expected long-run extreme poverty rate by 160 percent.

The attribution of causality to these findings requires the assumption that the patterns of violence were exogenous to victims' ex-ante perceived prospects for 
upward mobility. Causal attribution would not be appropriate if armed groups victimized hopeless subjects more severely than other victims. While this kind of targeting seems most unlikely -if anything armed groups in Colombia targeted community activists and leaders who would be expected to have ex ante higher mobility prospects (Centro Nacional de Memoria Histórica [CNMH], 2013)—our data come from a particular time and a place in which armed groups were directly competing for terrain and eschewed targeted for indiscriminate violence towards the civilian population (CNMH 2013). In fact, we demonstrate that the variation in the severity of violence is not correlated with victim's observable ex-ante characteristics. Moreover, we test for the robustness of our results using the subsample of our subjects who were victimized en masse with clearly no individual targeting. Finally, our results on the underlying psychological mechanism lend further credence to the notion that our estimated effect of violence is explained by the consequences of the traumatic exposure per se and not by a pattern of violence that targeted those with low mobility.

Our paper speaks to an emerging body of empirical work on the formation and effects of hope and aspirations. Most of this work has focused on the effects of positive interventions such as child sponsorship programs (Glewee, Ross, and Wyddick, 2017), conditional cash transfers (Chiapa, Campos-Vasquez, Huffman, and Santillán, 2012), exposure to norms, role models, or vicarious experiences of success (Beaman, Duflo, Pande, and Topalova, 2012; Jensen and Oster, 2009; Bernard, Dercon, Orkin, and Taffesse, 2014), financial inclusion (Chiapa, Prina, and Parker, 2016), and social interactions with local leaders (Macours and Vakis, 2014). ${ }^{3}$ By and large, these studies provide evidence on how the provision of information and relief of material constraints has positive impacts on the

\footnotetext{
3 Related studies have also identified that asking individuals to set their goals is enough to improve performance and outcomes among micro entrepreneurs (Cassar and Wydick, 2014) and university students (Hiller and Moya, 2017).
} 
aspirations of the poor, and on the existence of psychological multipliers that can create virtuous cycles.

To date, however, there is few evidence on how hope and beliefs change following adverse shocks. The study more closely related to ours is the work of Kosec and Hyunjung (2017), who analyze how a natural disaster affected aspirations in rural Pakistan. After controlling for households' education, expenditures, and wealth, they find that households who were exposed to a more severe rainfall shock lowered their aspirations but that access to government transfers ameliorated such negative impacts. These results thus suggest that adverse shocks shape create internal constraints, and that social protection programs can ease such burdens.

We contribute to the literature in different ways: First, we provide novel evidence on the effect of violence on expected upward mobility. Second, and perhaps more important, by bringing together data on material losses, subjective beliefs, and psychological trauma, we separately identify the role of internal constraints that stem from violence and how they influence individuals' beliefs. Third, we provide a novel way to elicit perceived prospects of upward mobility that builds upon and contributes to the recent work on measuring subjective beliefs (see Delavande, Gine, and McKenzie, 2011). Finally, we also contribute to the literature on the economic and behavioral consequences of violence and highlight a different channel through which violence can affect behavior and poverty dynamics (Bauer, Cassar, Chytilova, and Heinrich, 2014; Bellows and Miguel, 2009; Blattman, 2009; Callen, Isaqzadeh, Long, and Sprenger, 2014; Cassar, Grosjean, and Whitt, 2016; Cassar, Grosjean, and Whitt, 2014; Moya, 2017; and Voors et al., 2012).

In section VI, we conclude our paper by discussing the policy framework for victims of violence in Colombia and illustrating how standard asset-transfer programs may be unable to alter long-run poverty dynamics for many victims of 
violence. In doing so, we emphasize the importance of rethinking the strategies to assist the socioeconomic recovery of the victims of violence and other populations exposed to traumatic shocks.

\section{Violence and Trauma in Colombia: Context and Conceptual Framework}

Colombia has endured decades of violence and civil conflict. In the late 1940s, political disputes and decades of tension between landlords and peasants led to a period of civil conflict known as La Violencia (1948-1958). Despite the signing in 1958 of a peace agreement, violence persisted and leftist guerrillas and rightwinged paramilitary groups emerged soon after. Starting in the 1980's, illegal armed groups became heavily involved in the illicit drug production and trade, leading to the escalation of violence and to increasing patterns of civilian victimization (CNMH, 2013). In the last decade, conflicts dynamics were altered by three major events: the demobilization of paramilitary groups in 2006; the emergence of neo-paramilitary factions that clashed for the control of regions previously under paramilitary control; and the demobilization in 2017 of the Revolutionary Armed Forces of Colombia (FARC), the largest and oldest guerrilla group in the hemisphere. Our data were collected prior to the 2017 demobilization of the FARC, as mentioned above, during the time period in which FARC and neo-paramilitary forces were contesting for new terrain.

Throughout these decades of civil conflict, violence towards civilians has not been accidental. Instead, it has been a deliberate strategy of armed groups who rely on vicious and indiscriminate violence to spread fear and gain control of contested territories (CNMH, 2013). As a result, more than 8.5 million civilians have been victimized since 1985, including 7.3 million internally displaced persons (IDPs) (National Victims Unit, n.d). The latter figure represents 15 
percent of the country's population, and is the highest in the world (United Nations High Commissioner for Refugees [UNHCR], 2016).

Prior evidence has demonstrated that violence causes a severe loss of assets, which drives victims into poverty (Ibáñez and Moya, 2010a, 2010b). Victims, who by and large are displaced from rural to urban areas, abandon their lands and productive assets, are unable to find suitable employment opportunities since their agricultural skills are not well suited for urban labor markets, and lose their social networks. This massive loss of physical, human, and social capital hinders income generating activities and increases the vulnerability to poverty.

Victims' perceived prospects of upward mobility will likely be damaged by the external constraints imposed by the such loss of assets and by the descent into poverty. Building on work of Appadurai (2004), Ray (2006), and Duflo (2012), this can occur through two mechanisms: First, by the recognition that the loss of assets pushed them down the endowment space, imposes obvious obstacles for their ability to move out of poverty, and maybe even destined them to a lower level of wellbeing. Second, by the observation of poverty among victimized peers, which, following Ray's (2006) concept of an aspiration window, provides information on the limited opportunities for progress.

In addition, we hypothesize that victims can become hopeless and exaggerate the perceptions that moving out of poverty is unlikely through a psychological mechanism. Our hypothesis is motivated by previous research on the prevalence of psychological trauma among victims of violence and its implications on behavior. Victims of violence suffer an array of mood disturbances and psychopathologies, including anxiety, depression, complex trauma, and posttraumatic stress disorder (Briere and Spinazzola, 2005; Kessler, Sonnega, Bromet, Hughes, and Nelson, 1995; Mollica, McInnes, Poole, and Tor, 1988; Yehuda, 2002). In Colombia, for instance, victims have a high vulnerability to psychological trauma (Richards et al., 2011; Shultz et al., 2014), which follows a 
dose-response relationship — that is, more severe and recent violence brings about higher symptoms of trauma (Doctors Without Borders, 2010; Moya, 2017).

More important for our discussion, the nature of traumatic experiences can overwhelm the victims' coping resources and perpetuate states of avoidance. This process reduces their willingness to correct their exaggerated beliefs and to restore their emotional wellbeing. As a result, violence may induce pessimistic explanatory styles and hopelessness thus creating internal constraints (Sympson, 2000; Yehuda, 2002). ${ }^{4}$ Moreover, building upon the learned helplessness theory of depression (Seligman, 1975; Garber and Seligman, 1980), victims’ may remain hopeless even when there are pathways for recovery-in our context, when no material poverty trap exists. ${ }^{5}$

Taken together, the research above on the psychological consequences of violence suggests that victims may magnify the obstacles for upward mobility and incorrectly perceive that there are no prospects for real transformation. ${ }^{6}$ In doing so, violence may hinder economic behavior and alter poverty dynamics. This perspective is amplified by de Quidt and Haushoffer (forthcoming), who argue that depression, induced by the trauma of violence in our case, further undercuts individuals' self-efficacy and economic performance. ${ }^{7}$

\footnotetext{
4 The loss of agency is also related to a shift towards an external locus of control; the perception that the individual is unable to control the factors that shape her life (Rotter, 1966).

5 Barrett, Carter and Chavas (forthcoming) discuss the co-existence and interactions between material and psychological poverty traps.

6 Our study is not entirely new, or at least not in the Colombian context. Writing in the 1960's, a few years after the period of La Violencia had concluded, Lipman and Havens (1965) compared the degree of personality disorganization between a small sample of subjects who had been displaced during this period of civil conflict, and a sample of urban poor. Among others, they found that victims did not look forward to the future, which the authors interpreted as being a sign of hopelessness. In our paper, we provide more recent and rigorous evidence to answer this question.

7 While de Quidt and Haushoffer (forthcoming) largely draw on the clinical literature, Allousch (2017) shows using panel living standards data that depression shocks indeed reduce living standards.
} 


\section{Sample Design and Data}

We employ a complex array of data, including exposure to violence, perceived prospects of upward mobility, psychometric measures, as well as conventional living standards data. After reviewing the sample design, in this section we detail the instruments employed to collect these data and present descriptive statistics in each of these core areas.

\section{A. Sample Design}

In 2011, we conducted fieldwork in the departments of Bolivar, Córdoba, and Sucre, in Colombia's Atlantic region, and Tolima, in the Central region. We chose these departments as a first step to address the concerns of violence having been targeted and correlated with ex-ante hopes and beliefs. These departments had experienced increasing levels of violence as a result of the struggles between different armed groups for the control of three geographical corridors. ${ }^{8}$ Consistent with the dynamics of civilian victimization in civil conflicts (Kalyvas, 2006), anecdotal evidence suggests that armed groups relied on vicious and indiscriminate violence towards civilians to spread fear among the population and gain control of these strategic and contested regions (Human Rights Watch, 2010; Instituto de Estudios para el Desarrollo y la Paz [Indepaz], 2011; CNMH, 2013). This pattern of violence makes it likely that the severity of violence experienced by any particular individual should be orthogonal to individual characteristics, creating quasi-experimental variation in the severity of exposure to violence.

In each department, we used administrative data from the National Victims Unit to identify the main municipalities of residence of victims who had been

\footnotetext{
8 In the Atlantic region, neo-paramilitary groups emerged after the paramilitary peace demobilization in 2006 and clashed over control of the Nudo del Paramillo and Montes the María-two corridors with favorable conditions for the illegal drug trade (Human Rights Watch, 2010; Indepaz, 2011). In the Central region, the FARC retreated to the Cañon de las Hermosas - a corridor in the Central Andes that facilitates the movement of troops and the trafficking of illegal drugs to the Pacific Ocean, after the Colombian military intensified its operations against this group in 2004 (National Ombudsman's Office, 2009).
} 
victimized and displaced from the vicinity of the above corridors. ${ }^{9}$ We visited these municipalities and organized community meetings where we explained the projects' objectives, including the recall of experiences of violence, and highlighted that participation was voluntary and that participants could opt-out at any time. ${ }^{10}$ In each meeting, we invited one-third of interested individuals to participate. $^{11}$

We sampled 344 victims of violence who had been victimized in, and displaced from, the rural areas of 34 different municipalities and resided in the urban locations where fieldwork was conducted. ${ }^{12}$ The sample includes 132 individuals from nine different villages who had been victimized and displaced en masse by cross fire from armed groups. In the context of these mass displacements, individual targeting was likely non-existent. Figure A1 in the Appendix illustrates the geographical distribution of the municipalities from which victims were displaced, and of the intensity of displacement to highlight how the regions where we conducted fieldwork had been torn by violence.

\section{B. Data}

In each municipality, enumerators first administered a household survey during weekdays. After all surveys were completed, we organized weekend sessions where enumerators first administered the victimization questionnaire and

\footnotetext{
9 Departmental capitals: Sincelejo and Ibagué in the departments of Sucre and Tolima, respectively. Urban centers: Tierralta and Montelíbano in the department of Córdoba.

10 These meetings were organized with the support of local government officials, ombudsmen and Catholic priest, all of whom were recognized and trusted by victimized and displaced communities. Their support was instrumental to overcome some of the challenges of conducting fieldwork in contexts of civil conflict, such as interacting with victims, obtaining their trust, ensuring the safety of participants, and collecting sensitive information on the exposure to violence.

More than 90 percent of invited subjects accepted to participate. Subjects who declined had been victimized very recently (less than 6 months before) and it is likely that they were suffering from severe symptoms of trauma. If we indeed sampled the relatively less traumatized, this would work against our hypothesis. Nevertheless, the rate of non-response is low considering the context, and we were able to sample subjects experiencing severe symptoms of trauma.

12 Moya (2017) uses this sample and data to analyze the effect of violence on risk attitudes. To rule out endogenous geographic sorting, he further restricts the analysis to 284 victims who had also resided in the region for more than 10 years. In our paper and in Moya (2017) results are robust if we use the full sample, or the more restrictive sample.
} 
psychometric scale in private, and we then led a group activity to elicit subjects' perceived prospects of upward mobility. Since we collected sensitive data and conducted fieldwork in municipalities torn by violence, data were collected at the local church to guarantee safe, private, and trusted environments for respondents and enumerators. ${ }^{13}$ We describe each instrument below and provide sample statistics. Foreshadowing our later econometric analysis that exploits variation in exposure to violence, we separately examine descriptive statistics for households exposed to moderate levels of violence (less than the median exposure) and those exposed to severe levels of violence.

Household victimization questionnaire.-At the beginning of the weekend session, enumerators privately administered a victimization questionnaire that measured whether a household member experienced different violent events, and the number of times that each event had occurred in the last 10 years. We use the number of violent events experienced by the household as a measure for the severity of violence. ${ }^{14}$ In addition, we use the number of years since the displacement as a proxy for the temporal proximity of violence. ${ }^{15}$

Panel A of Table 1 presents sample statistics on the nature and severity of the exposure to violence and highlights three important features: First, all subjects in the sample had been displaced and 93 percent of them had been exposed to at least one violent event. ${ }^{16}$ The most frequent events included being threatened by an armed group (55\%), being caught in the cross fire of armed combat $(50 \%)$,

\footnotetext{
13 Moya (2017) describes the ethical considerations in collecting sensitive data from victims, and the strategies we implemented to mitigate negative effects on subjects. These include, stressing that participation was voluntary and that subjects could skip specific questions or entire modules, defining a protocol for treatment of special cases, and special training prior to fieldwork on strategies for emotional containment.

14 We also measure the severity of violence through a victimization score constructed through principal component analysis. The results are robust if we use the victimization score in the empirical analysis, and available upon request.

${ }^{15}$ Although violent events did not necessarily occur at the same time, subjects stated that their displacement was triggered by a peak in violence. The number of years since the displacement therefore captures the temporal proximity of the moment when violence was at its highest.

16

In Table 1 and in the rest of the analysis, we drop 8 outliers who reported a number of violent events more than 5 standard deviations above the mean. Results are robust if we keep these observations.
} 
suffering the assassination of a household member (24\%), suffering a violent attack (15\%), and/or experiencing and surviving a massacre (8\%). Second, subjects had been exposed to an average of 6.6 violent events and the victimization occurred 2.5 years on average before the data collection. Third, there is considerable variation in the severity and temporal proximity of violence.

TABLE 1 -EXPOSURE TO VIOLENCE

\begin{tabular}{|c|c|c|c|}
\hline & $\begin{array}{c}\text { Total } \\
\text { [1] }\end{array}$ & $\begin{array}{c}\text { Moderate } \\
\text { [2] }\end{array}$ & $\begin{array}{c}\text { Severe } \\
{[3]}\end{array}$ \\
\hline \multicolumn{4}{|l|}{ A. Exposure to Violence } \\
\hline \multirow[t]{2}{*}{ Victim: exposed to at least one event $(=1)$} & 0.93 & 0.88 & 1.00 \\
\hline & [0.253] & {$[0.321]$} & {$[0]$} \\
\hline \multirow[t]{2}{*}{ Severity: number of violent events } & 6.64 & 2.04 & 13.25 \\
\hline & [8.293] & [1.229] & {$[9.563]$} \\
\hline \multirow[t]{2}{*}{ Temporal proximity: years since violence } & 2.52 & 2.50 & 2.55 \\
\hline & [3.318] & [3.410] & [3.193] \\
\hline Hh member exposed to a combat $(=1)$ & $\begin{array}{c}0.50 \\
{[0.501]}\end{array}$ & $\begin{array}{c}0.34 \\
{[0.476]}\end{array}$ & $\begin{array}{c}0.73 \\
{[0.445]}\end{array}$ \\
\hline Hh member exposed was threatened $(=1)$ & $\begin{array}{c}0.55 \\
{[0.498]}\end{array}$ & $\begin{array}{c}0.44 \\
{[0.498]}\end{array}$ & $\begin{array}{c}0.71 \\
{[0.455]}\end{array}$ \\
\hline Hh member suffered the assassination of a hh member $(=1)$ & $\begin{array}{c}0.24 \\
{[0.430]}\end{array}$ & $\begin{array}{c}0.13 \\
{[0.333]}\end{array}$ & $\begin{array}{c}0.41 \\
{[0.494]}\end{array}$ \\
\hline Hh member exposed to an attack $(=1)$ & $\begin{array}{c}0.15 \\
{[0.359]}\end{array}$ & $\begin{array}{c}0.05 \\
{[0.209]}\end{array}$ & $\begin{array}{c}0.30 \\
{[0.462]}\end{array}$ \\
\hline Hh member exposed to a massacre $(=1)$ & $\begin{array}{c}0.08 \\
{[0.272]}\end{array}$ & $\begin{array}{c}0.02 \\
{[0.122]}\end{array}$ & $\begin{array}{c}0.17 \\
{[0.380]}\end{array}$ \\
\hline Hh member was ordered to migrate $(=1)$ & $\begin{array}{c}0.42 \\
{[0.494]}\end{array}$ & $\begin{array}{c}0.36 \\
{[0.482]}\end{array}$ & $\begin{array}{c}0.49 \\
{[0.502]}\end{array}$ \\
\hline Hh member exposed to another violent event $(=1)$ & $\begin{array}{c}0.26 \\
{[0.439]}\end{array}$ & $\begin{array}{c}0.14 \\
{[0.344]}\end{array}$ & $\begin{array}{c}0.44 \\
{[0.498]}\end{array}$ \\
\hline \multicolumn{4}{|l|}{ B. Psychological Trauma - \% Above Cutoff $(\mathrm{T}>63)$} \\
\hline Depression & $\begin{array}{c}0.38 \\
{[0.486]}\end{array}$ & $\begin{array}{c}0.35 \\
{[0.478]}\end{array}$ & $\begin{array}{c}0.42 \\
{[0.495]}\end{array}$ \\
\hline Anxiety & $\begin{array}{c}0.26 \\
{[0.439]}\end{array}$ & $\begin{array}{c}0.23 \\
{[0.423]}\end{array}$ & $\begin{array}{c}0.30 \\
{[0.459]}\end{array}$ \\
\hline PTSD & $\begin{array}{c}0.21 \\
{[0.405]}\end{array}$ & $\begin{array}{c}0.17 \\
{[0.378]}\end{array}$ & $\begin{array}{c}0.25 \\
{[0.437]}\end{array}$ \\
\hline Observations & 336 & 198 & 138 \\
\hline
\end{tabular}

Notes: Summary statistics on household-level exposure to violence and symptoms of psychological trauma. Columns 1 reports sample statistics for the full sample, while columns 2 and 3 report statistics according to an arbitrary stratification of the data: whether the household was exposed to a number of violent events that were below (moderate violence) or above (severe violence) the median number of violent events. Standard deviations are reported in brackets. 
Panel A of Table 1 presents sample statistics on the nature and severity of the exposure to violence and highlights three important features: First, all subjects in the sample had been displaced and 93 percent of them had been exposed to at least one violent event. ${ }^{17}$ The most frequent events included being threatened by an armed group (55\%), being caught in the cross fire of armed combat (50\%), suffering the assassination of a household member (24\%), suffering a violent attack (15\%), and/or experiencing and surviving a massacre (8\%). Second, subjects had been exposed to an average of 6.6 violent events and the victimization occurred 2.5 years on average before the data collection. Third, there is considerable variation in the severity and temporal proximity of violence.

Psychometric Scale.-Next, enumerators privately administered a locally adapted version of the Symptoms Checklist 90 R (SCL 90-R). This scale measured the experience of symptoms that are associated with different manifestations of psychological trauma, such as headaches, back pains, and uneasiness among others, over the previous three months. ${ }^{18}$ The responses to different subsets of symptoms provide measures of the extent and severity of nine different psychopathologies, including depression, anxiety, and a global severity index (GSI). ${ }^{19}$ These measures include a continuous standardized T-score and an indicator variable that denotes whether the subject scores above a critical threshold $\left(\mathrm{T}_{\mathrm{i}}>63\right)$ and is at risk of developing a clinical psychopathology. ${ }^{20}$

\footnotetext{
17 In Table 1 and in the rest of the analysis, we drop 8 outliers who reported a number of violent events more than 5 standard deviations above the mean. Results are robust if we keep these observations.

18

The SCL 90-R has reliable psychometric properties and has been widely implemented in developing countries and in conflict scenarios (Casullo, 2004). For this sample, the Cronbach alpha of 0.94 indicates an excellent internal consistency - the extent to which all items measure the same constructs.

19 The GSI measures the overall severity of symptoms of psychological trauma.

20 Responses for each question are scaled from 0 to 4 , indicating a range of no symptoms to daily symptoms in the last three months. Scores on the relevant questions for each psychopathology are added and divided by the total number of questions answered. Then, a T-score is standardized with mean 50 and standard deviation 10: $\left(\mathrm{T}_{\mathrm{i}}=10+50 \times\right.$ score $)$.
} 


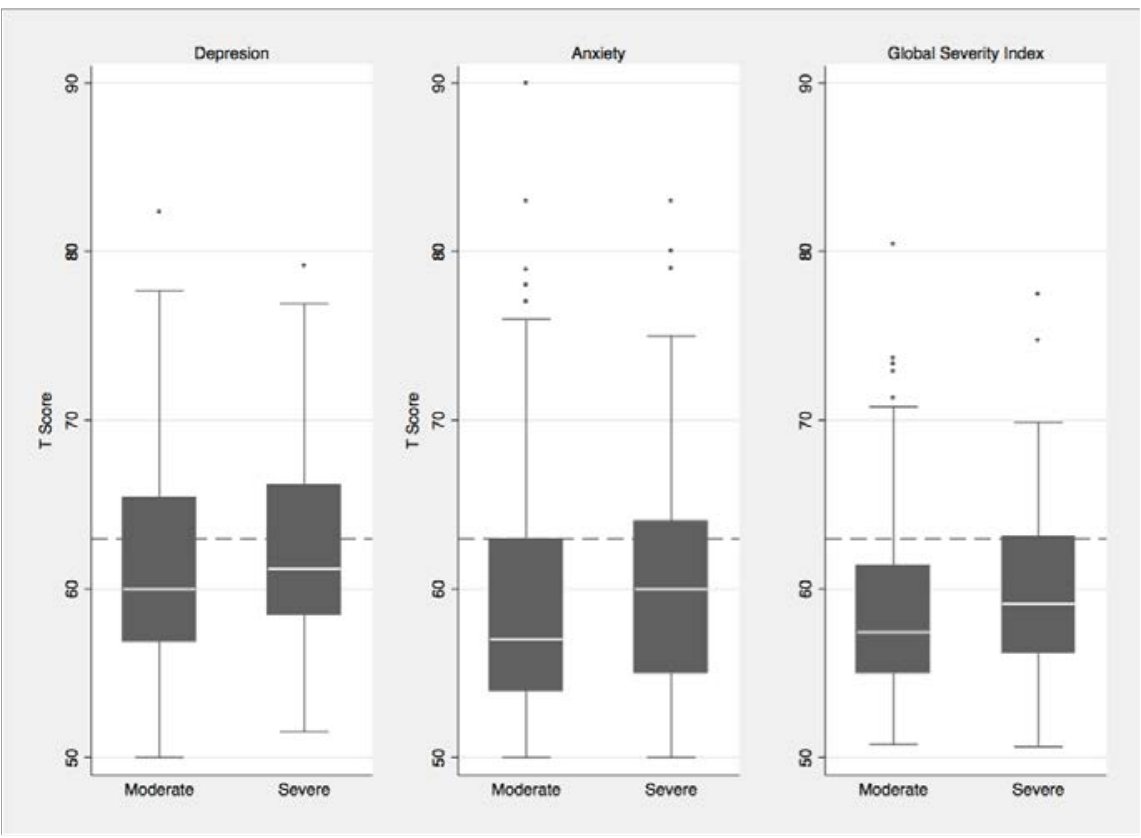

FIGURE 1. PSYCHOLOGICAL TRAUMA

Notes: Box-plot distribution of depression and anxiety, and the Global Severity Index. Sample statistics are reported according to an arbitrary stratification of the data: whether the household was exposed to a number of violent events that were below (moderate violence) or above (severe violence) the median number of violent events. The dotted line depicts the level above which individuals are at risk of developing clinical cases.

Figure 1 illustrates the box-plot distributions of the depression, anxiety, and GSI scores according to whether subjects had been exposed to moderate or severe violence as previously defined. The dotted line in each plot indicates the threshold above which a subject is considered at risk. In conformity with the studies in clinical psychology, the data suggests that the psychological consequences of violence follow a dose-response relationship: a more severe experience of violence brings about more symptoms of depression and anxiety and of psychological trauma in general — that is, a higher GSI score. Moreover, at the time of the data collection, 38 and 26 percent of the subjects were at risk of developing depression and anxiety disorders, respectively (see Table 1, Panel B). 
These figures are higher among the group exposed to severe violence and considerably higher than those for the Colombian population (Moya, 2017). ${ }^{21}$

Perceived Prospects of Upward Mobility.-At the end of the weekend session, we conducted a group activity to elicit victims' pre-violence and current living standards and their perceived prospects of upward mobility. For this purpose, we built upon the work of Krishna $(2004,2006,2010)$ and Narayan, Pritchett, and Kapoor (2009), and designed a six-step ladder of life that portrayed different levels of living standards among victimized communities. ${ }^{22}$ We characterized each step of the ladder over five dimensions-housing, land, labor income, children's schooling, and consumption. To ensure that our ladder of life provided an accurate representation of the living standards of victims of violence, we characterized each step based on the World Bank's Moving Out of Poverty Colombia case study, which constructed ladders of life for victimized and nonvictimized communities across the country (see Matijasevic, et al., 2007; and Narayan and Petesch, 2010). In our ladder, the bottom two steps illustrated the more salient characteristics of victims living in extreme poverty, whereas the top three steps portrayed the characteristics of non-poor victims (see Figure 2). ${ }^{23}$

We measured subjects' perceptions using the ladder of life as follows: First, we explained that we wanted to understand the socioeconomic changes that occurred to each participant as a result of their exposure to violence and their displacement. To this end, we introduced the ladder of life, used visual aids to describe the

\footnotetext{
21

Appendix Table A1 provides a more detailed characterization of the scores of the 9 psychopathologies captured by the SCL-90 for the full sample and the sample of subjects who were victimized en masse.

22 The "stages of progress" approach of Krishna (2004, 2006, 2010) and the "ladder of life" approach of Narayan, Pritchett, and Kapoor (2009) have been used to identify how the poor understand poverty and the strategies, pathways, and major life events that have affected individual and community poverty dynamics. This is often carried out during focus groups where participants define the different levels of wellbeing or living standards (stages of progress or steps in the ladder of life) within a community. Participants then describe the characteristics of each level, identify where the community poverty line would be located, and discuss the pathways in which households move out or into poverty. defined a single ladder of life for all groups. This allowed us to: (1) compare victims' perceptions regardless of the municipality and community in which they were residing at the time of fieldwork; and (2) resemble comparable pre and post-violence living standards to identify movements up or down the ladder of life over this period.
} 
characteristics at each step, and provided examples of upward, stagnant, and downward mobility not related to violence. Subjects received a booklet with the illustration of the ladder, and placed a stone at the step that resembled their household's pre-violence living standards, and another one for the current living standards. This was carried out in private, with the assistance of enumerators.

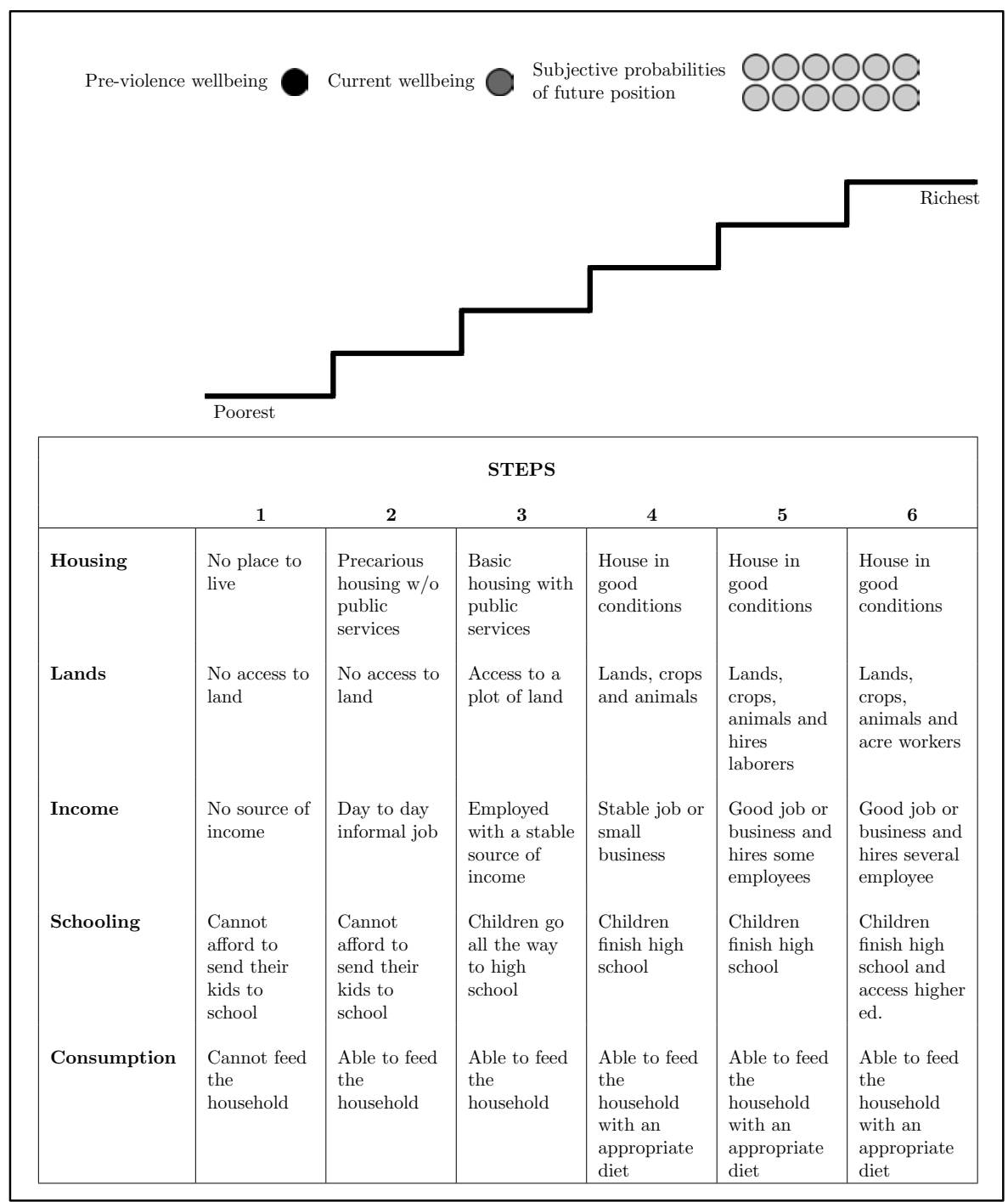

FIGURE 2. LADDER OF LIFE

Notes: Graphical depiction of the ladder of life. Each step of the ladder was characterized over 5 dimensions (housing, lands, income, schooling, and consumption). Subjects were first asked to place one stone at the step that resembled their living standards before the episodes of violence, and a different one for the current living standards. Then, they were asked to distribute 12 stones in the steps of the ladder where they believed they could end up in the following year. 
Second, we explained that we also wanted to understand how participants perceived their future. For this purpose, we built upon recent work on the elicitation of subjective probabilities of future events without explicitly referring to the concept of probabilities (see Delavande, Gine, and McKenzie, 2011). We handed out 12 stones to each subject and asked them to place them in the steps of the ladder of life where they thought they could end up in the following year. To explain this activity, we only mentioned that they should place more (less) stones in a step if they thought that it was more (less) likely that they would be able to achieve those living standards in a year. After this explanation, subjects placed the 12 stones over the ladder of life depicted in the booklet and enumerators recorded their answers. The relative number of stones at each step provides a measure of the subjective probability of reaching that position on the ladder.

Figure 3 illustrates the distributions of pre-violence and current positions on the ladder of life, and the distributions for the subjective probabilities of being at each step in the following year. ${ }^{24}$ The data in the first panel indicates that before the episodes of violence, 37 percent of the subjects were in extreme poverty-at the first two steps of the ladder-, 44 percent were at the $3^{\text {rd }}$ step, and 18 percent were at or above the $4^{\text {th }}$ step. Moreover, we observe minor differences in the distributions between subjects exposed to moderate and severe violence. Consistent with the work of Ibáñez and Moya (2010a, 2010b), the data in the second panel indicates that violence and displacement drove victims into poverty and condensed the asset and income distributions downwards. Overall, 91 percent of the subjects reported that they were currently in extreme poverty, while less than two percent were at or above the $4^{\text {th }}$ step. In this case, we observe differences according to the severity of violence; while 86 percent of the subjects exposed to moderate violence reported that they were currently at the bottom two

\footnotetext{
24 Table A2 in the Appendix reports the averages for pre-violence and current locations in the ladder, as well as the average probabilities for being at each step of the ladder in the next year, and two-sample mean differences.
} 
steps of the ladder, this figure increases to 96 for those exposed to severe violence.
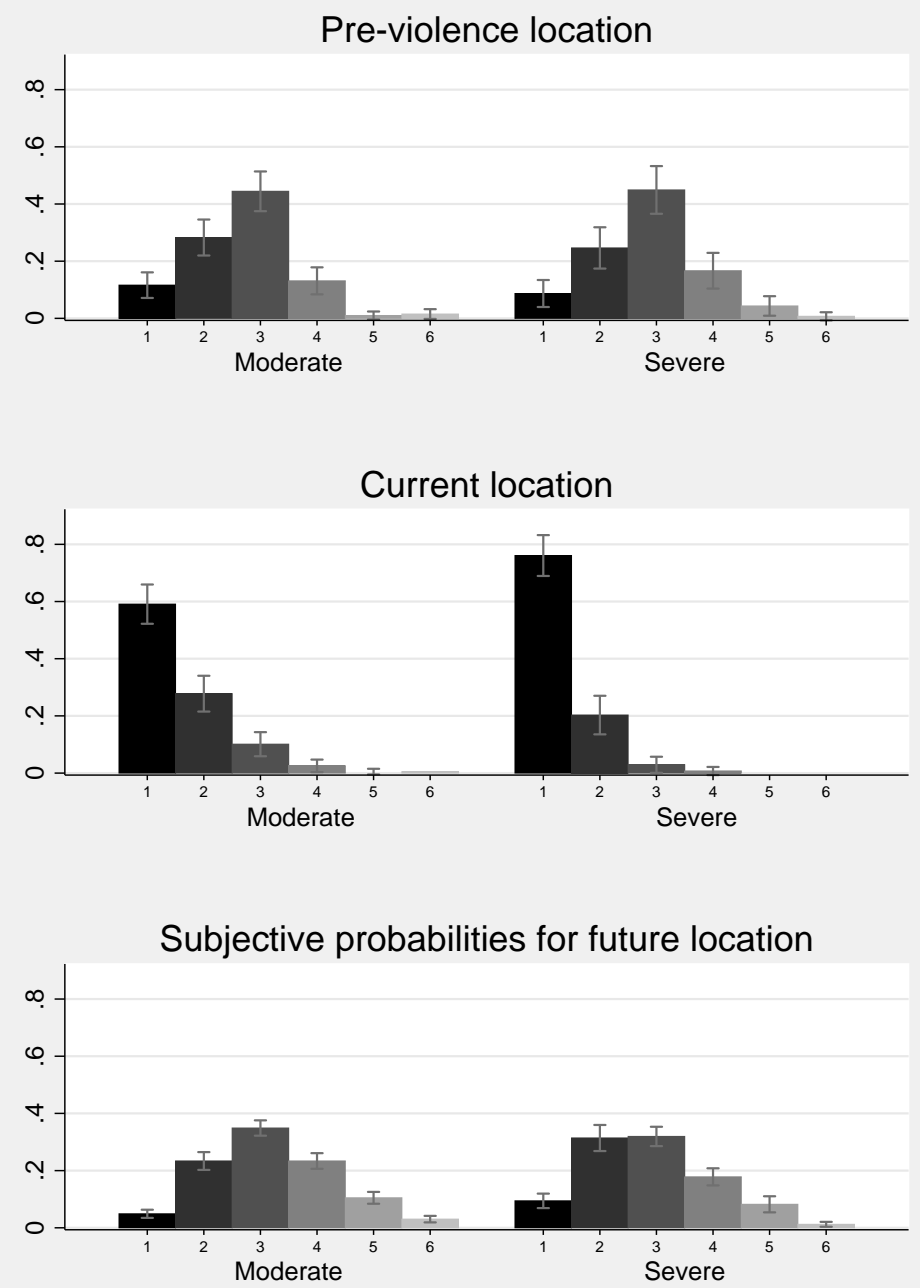

Figure 3. PASt AND CuRRent Positions AND PERCEIVEd Prospects of UpWARd MoBiLity

Notes: Box-plot distribution of the pre-violence and current positions on the ladder, and on the subjective probabilities of reaching each step of the ladder within a year. The data is stratified according to whether the household was exposed moderate or severe violence as defined previously.

Finally, the bottom panel of Figure 3 illustrates the perceived prospects for each step of the ladder. The data in the figure first indicates that the victims in the sample are somewhat optimist. Although most victims fell to the bottom of the 
ladder, the distributions of subjective probabilities for future positions resemble and even exceed the distributions of pre-violence positions. However, when we stratify the data according to the severity of violence, we observe that those who were exposed to more severe violence appear more hopeless. Whereas subjects who experienced moderate violence perceive that the probability of being in extreme poverty is 28 percent on average, this figure increases to 41 percent for those who experienced severe violence (a 46 percent increase).

Household Survey.-Enumerators administered a household survey prior to collection of the violence and psychometric data described above. The survey captured information on current and retrospective socioeconomic and demographic characteristics of subjects and their households. The latter allow us to characterize the households' pre-violence and analyze whether the severity of violence was associated with specific characteristics. The survey also included a question on whether subjects looked towards the following year with hope and optimism or with hopelessness and despair, and a Likert scale question on whether they believed that it was likely, unlikely, or very unlikely that their economic circumstances will improve in a year. These questions provide alternative measures of the degree of hopelessness and allow us to assess the validity of the perceived prospects of upward mobility described above.

Table 2 reports sample statistics and differences between the current and retrospective characteristics of subjects exposed to moderate and severe violence. The data in panels $\mathrm{A}$ and $\mathrm{B}$ indicates that there are no significant differences between subjects who were moderately and severely victimized, other than their current age, and the household's pre-violence participation in community organizations. While organizational membership is not the same thing as being a community leader, which according to CNMH (2013) were sometimes targeted in other areas of the country, this unexpected statistic motivates subsequent robustness tests. Nevertheless, as discussed previously, the targeting of 
households who participate or lead community organizations would work against the hypothesis that violence dampens mobility prospects.

TABle 2-SAMPle Balance: PRE-VIOlence \& CURRENT Characteristics

\begin{tabular}{|c|c|c|c|}
\hline & $\begin{array}{c}\text { Total } \\
{[1]} \\
\end{array}$ & $\begin{array}{c}\text { Moderate } \\
{[2]}\end{array}$ & $\begin{array}{c}\text { Severe } \\
{[3]}\end{array}$ \\
\hline \multicolumn{4}{|l|}{ A. Current characteristics } \\
\hline Age & $\begin{array}{c}41.05 \\
{[13.32]}\end{array}$ & $\begin{array}{c}39.70 \\
{[12.96]}\end{array}$ & $\begin{array}{c}42.99 * * \\
{[13.64]}\end{array}$ \\
\hline Male $(=1)$ & $\begin{array}{c}0.39 \\
{[0.488]}\end{array}$ & $\begin{array}{c}0.38 \\
{[0.486]}\end{array}$ & $\begin{array}{c}0.41 \\
{[0.493]}\end{array}$ \\
\hline Household Head (=1) & $\begin{array}{c}0.78 \\
{[0.415]}\end{array}$ & $\begin{array}{c}0.80 \\
{[0.399]}\end{array}$ & $\begin{array}{c}0.75 \\
{[0.437]}\end{array}$ \\
\hline Literate $(=1)$ & $\begin{array}{c}4.47 \\
{[2.035]}\end{array}$ & $\begin{array}{c}4.59 \\
{[1.930]}\end{array}$ & $\begin{array}{c}4.30 \\
{[2.173]}\end{array}$ \\
\hline Household size & $\begin{array}{c}0.82 \\
{[0.381]}\end{array}$ & $\begin{array}{c}0.83 \\
{[0.378]}\end{array}$ & $\begin{array}{c}0.82 \\
{[0.387]}\end{array}$ \\
\hline Log yearly per capita consumption ( $\$ \mathrm{COP})$ & $\begin{array}{c}3.80 \\
{[0.864]}\end{array}$ & $\begin{array}{c}3.76 \\
{[0.835]}\end{array}$ & $\begin{array}{c}3.85 \\
{[0.904]}\end{array}$ \\
\hline \multicolumn{4}{|l|}{ B. Ex-ante (pre-displacement) characteristics } \\
\hline Household head was male $(=1)$ & $\begin{array}{c}0.66 \\
{[0.474]}\end{array}$ & $\begin{array}{c}0.65 \\
{[0.478]}\end{array}$ & $\begin{array}{c}0.68 \\
{[0.469]}\end{array}$ \\
\hline Highest level of education in the household (years) & $\begin{array}{c}8.49 \\
{[3.697]}\end{array}$ & $\begin{array}{c}8.63 \\
{[3.581]}\end{array}$ & $\begin{array}{c}8.28 \\
{[3.861]}\end{array}$ \\
\hline Household main activity was off-farm labor $(=1)$ & $\begin{array}{c}0.47 \\
{[0.500]}\end{array}$ & $\begin{array}{c}0.47 \\
{[0.501]}\end{array}$ & $\begin{array}{c}0.47 \\
{[0.501]}\end{array}$ \\
\hline Household main activity was agriculture $(=1)$ & $\begin{array}{c}0.59 \\
{[0.494]}\end{array}$ & $\begin{array}{c}0.57 \\
{[0.497]}\end{array}$ & $\begin{array}{c}0.61 \\
{[0.489]}\end{array}$ \\
\hline Lands owned $(\mathrm{Ha})$ & $\begin{array}{c}7.22 \\
{[23.05]}\end{array}$ & $\begin{array}{c}6.09 \\
{[15.14]}\end{array}$ & $\begin{array}{c}8.86 \\
{[31.06]}\end{array}$ \\
\hline Hh head participated in at least one social organization $(=1)$ & $\begin{array}{c}0.44 \\
{[0.498]}\end{array}$ & $\begin{array}{c}0.40 \\
{[0.491]}\end{array}$ & $\begin{array}{c}0.50^{*} \\
{[0.502]}\end{array}$ \\
\hline \multicolumn{4}{|l|}{ C. Hopelessness - Survey Measures } \\
\hline Looks towards the following year with hopelessness and despair $(=1)$ & $\begin{array}{c}0.55 \\
{[0.499]}\end{array}$ & $\begin{array}{c}0.49 \\
{[0.501]}\end{array}$ & $\begin{array}{l}0.62 * * \\
{[0.486]}\end{array}$ \\
\hline Highly unlikely that economic circumstances will improve $(=1)$ & $\begin{array}{c}0.31 \\
{[0.463]}\end{array}$ & $\begin{array}{c}0.25 \\
{[0.433]}\end{array}$ & $\begin{array}{c}0.40^{* * *} \\
{[0.491]}\end{array}$ \\
\hline Observations & 336 & 198 & 138 \\
\hline
\end{tabular}

Notes: Panel A and B report data on subjects' current and pre-violence characteristics. Panel C reports data on the surveybased measures of hopelessness. Asterisks in column 3 indicate the significance of the mean-difference test between the moderate and severe victimization groups. Standard deviations reported in brackets. ${ }^{*} \mathrm{p}<0.1$. ${ }^{* *} \mathrm{p}<0.05$. $* * * \mathrm{p}<0.01$.

Finally, Panel $\mathrm{C}$ in Table 2 indicates that subjects exposed to more severe violence are more likely to look forward to the following year with hopelessness 
and perceive that it is highly unlikely that their economic circumstances will improve. These differences are consistent with the data in Figure 2, and thus suggest that subjects understood the tasks during the ladder of life activity and that the probabilities for being at each step of the ladder accurately portray their perceived prospects of upward mobility.

\section{The Effect of Violence on Perceived Prospects of Upward Mobility}

In this section, we first employ our quasi-experimental strategy to test whether more severe violence damages the perceived prospects of upward mobility. We then discuss the assumptions behind this empirical strategy and analyze the validity of our results using the sample of subjects who were victimized en masse. We further test the robustness of our results using alternative specifications of the econometric model and key variables. To conclude, we analyze the underlying psychological channel to highlight the role of internal constrains in shaping victims' perceived prospects of upward mobility.

\section{A. Violence and Perceived Prospects of Upward Mobility}

To analyze the effect of violence on victims' perceived prospects of upward mobility, we exploit the variation in the severity of violence, controlling for the current step of the ladder of life and other individual and household characteristics. This strategy allows us to compare subjects who were at the same step, and therefore faced similar external constraints, but who had been exposed to different levels of violence. In doing so, we highlight the effects stemming from the exposure to violence, which we hypothesize reflect the internal constrains created by such traumatic experiences.

For each future step of the ladder $k$, we estimate model 1 , where we regress $p\left(S_{h r}^{t+1}=k\right)$ - the perceived probability of being in step $k$ in the following year 
for household $h$ in region $r$-on $V_{h r}$, the standardized number of violent events to which the household $h$ was exposed, its quadratic term, and $\mathbf{I}\left(S_{h r}^{t}=j\right)$, a binary indicator for the current position on the ladder. Since few subjects were at or above the $4^{\text {th }}$ step of the ladder (see Figure 3), we condensed the top 3 steps into a single step that characterizes to the non-poor victims. ${ }^{25}$

$$
\begin{gathered}
p\left(S_{h r}^{t+1}=k\right)=\gamma_{0}+\gamma_{1} V_{h r}+\gamma_{2} V_{h r}^{2}+\sum_{j=1}^{4} \delta_{j} \mathbf{I}\left(S_{h r}^{t}=j\right)+ \\
\Gamma_{1}{ }^{\prime} X_{i}^{t}+\Gamma_{2}{ }^{\prime} X_{h}^{t-1}+\xi_{r}+\varepsilon_{h r}, \forall k \in[1,4]
\end{gathered}
$$

In model 1, we also control for a vector $X_{h r}^{t}$ of current individual covariates, such as each subject's age, gender, and years of education, which provide a measure of the subject's level of human capital. ${ }^{26}$ The matrix of current covariates also includes whether the subject is the household head, and whether the household experienced an economic shock or the death of a member for reasons not related to violence. We also control for a matrix $X_{h}^{t-1}$ of ex-ante household characteristics, including the size of the household's landholdings, which provides a measure of the extent of asset losses, whether agriculture was the households' main economic activity, and the pre-violence organizational membership variable, which Table 2 revealed to be unbalanced between the low and high severity exposure groups. Finally, the model includes a region-specific fixed effect $\xi_{r}$, and a White-robust error term $\varepsilon_{h r}$.

\footnotetext{
25 Results are robust if we estimate the system of equations on the six steps, as well as if we drop the controls for the current location on the ladder. Results are available upon request.

${ }^{26}$ We do not control for physical capital since few subject reported ownership or access to productive assets.
} 
TABLe 3-Violence \&Perceived Prospects of Upward Mobility

\begin{tabular}{|c|c|c|c|c|}
\hline & $\mathrm{p}($ Step $\mathrm{t}+1=1)$ & $\mathrm{p}($ Step $\mathrm{t}+1=2)$ & $\mathrm{p}($ Step $\mathrm{t}+1=3)$ & $\mathrm{p}($ Step $\mathrm{t}+1=4)$ \\
\hline \# of violent events (standardized) & $\begin{array}{c}0.036 * * * \\
{[0.013]}\end{array}$ & $\begin{array}{c}0.037 \\
{[0.024]}\end{array}$ & $\begin{array}{l}-0.016 \\
{[0.019]}\end{array}$ & $\begin{array}{c}-0.057 * * \\
{[0.028]}\end{array}$ \\
\hline \# of violent events squared (standardized) & $\begin{array}{l}-0.005 \\
{[0.005]}\end{array}$ & $\begin{array}{l}-0.009 \\
{[0.008]}\end{array}$ & $\begin{array}{l}0.008 \\
{[0.005]}\end{array}$ & $\begin{array}{c}0.005 \\
{[0.011]}\end{array}$ \\
\hline Step $\mathrm{t}=2$ & $\begin{array}{c}-0.038^{* *} \\
{[0.017]}\end{array}$ & $\begin{array}{c}-0.174 * * * \\
{[0.025]}\end{array}$ & $\begin{array}{c}0.080 * * * \\
{[0.029]}\end{array}$ & $\begin{array}{c}0.132 * * * \\
{[0.037]}\end{array}$ \\
\hline Step $t=3$ & $\begin{array}{c}-0.054 * * \\
{[0.023]}\end{array}$ & $\begin{array}{c}-0.255^{* * *} * \\
{[0.036]}\end{array}$ & $\begin{array}{l}-0.033 \\
{[0.044]}\end{array}$ & $\begin{array}{c}0.342 * * * \\
{[0.069]}\end{array}$ \\
\hline Step $t=4$ & $\begin{array}{c}-0.062 * * * \\
{[0.017]}\end{array}$ & $\begin{array}{c}-0.285 * * * \\
{[0.050]}\end{array}$ & $\begin{array}{l}-0.043 \\
{[0.087]}\end{array}$ & $\begin{array}{c}0.389 * * * \\
{[0.126]}\end{array}$ \\
\hline Constant & $\begin{array}{l}0.104 * \\
{[0.053]}\end{array}$ & $\begin{array}{c}0.382 * * * \\
{[0.075]}\end{array}$ & $\begin{array}{c}0.361 * * * \\
{[0.070]}\end{array}$ & $\begin{array}{l}0.153 \\
{[0.095]}\end{array}$ \\
\hline Hh exante and current controls & Yes & Yes & Yes & Yes \\
\hline R-squared & 0.10 & 0.25 & 0.08 & 0.21 \\
\hline Observations & 311 & 311 & 311 & 311 \\
\hline Mean value of dependent variable & 0.067 & 0.267 & 0.337 & 0.329 \\
\hline \multicolumn{5}{|c|}{$\begin{array}{l}\text { Notes: Each column reports the results of estimating model } 1 \text { on the perceived probabilities of being in each step of the } \\
\text { ladder of life in the following year. The table reports the coefficients for the severity of violence, measured by the } \\
\text { standardized number of all violent events to which a household was exposed, its quadratic term, and a binary indicator for } \\
\text { the current position on the ladder. The bottom step of the ladder is the omitted category. As described in equation } 1 \text {, each } \\
\text { model includes a set of current and ex-ante covariates and a regional fixed effect. Current covariates include the subject's } \\
\text { age, gender, and years of education, whether he or she is the household head, and whether the household experienced an } \\
\text { economic shock or the death of a household member for reasons not related to violence. Ex-ante covariates include the } \\
\text { household size, size of land holdings, participation of a household member in local organizations, and participation of the } \\
\text { household in agricultural work. Estimated coefficients of the covariates and fixed effect are not reported but are available } \\
\text { upon request. White-robust standard errors are reported in brackets. } * \mathrm{p}<0.10 \text {. } * * \mathrm{p}<0.05 \text {. } * * * \mathrm{p}<0.01 \text {. }\end{array}$} \\
\hline
\end{tabular}

As expected, the results also indicate that the current position on the ladder has a strong and significant effect on the perceived prospects of upward mobility. As subjects move up on the ladder of life and their circumstances improve, the perceptions of the likelihood of being in poverty fall, whereas those for moving up the ladder increase. For example, relative to subjects at the second step of the ladder, those at the bottom step perceive that the likelihood of remaining in the bottom of the ladder is 4 percentage points higher, while the likelihood of moving up to the top step is 13 percentage points lower. These results are intuitiveobjectively, it is more difficult for a subject at the bottom of the ladder to move to 
the top of the ladder in the span of a year than for subjects further up in the ladder. The results thus suggest that subjects accurately perceive how current socioeconomic circumstances and the related external constraints influence their prospects of upward mobility.

Taken together, the results in Table 3 indicate that subjects who were exposed to more severe violence perceive that they live in a different world, one with

diminished prospects for upward mobility. Since we compare subjects with similar living standards, the differences between two otherwise similar victims who were exposed to different levels of violence, point to the existence of persistent internal constraints by which violence begets hopelessness.

\section{B. Assumptions for Identification}

The attribution of causality to the results in Table 3 hinges on the assumption that the severity of violence was exogenous to pre-violence perceived prospects for upward mobility. The results would thus be biased if armed groups exerted more violence on individuals or households based on characteristics that were correlated with their ex-ante levels beliefs and levels of hope. While the information available for the time and place from which our data come suggest that violence was indiscriminate and random (see Section II), we replicate here the strategies used by Moya (2017) to test for the validity of this information and robustness of our results.

First, we analyze whether the severity of violence was based on ex-ante observable characteristics. In Table 2, we had observed that the households' participation in local organizations differed across the groups exposed to moderate and severe violence. In addition, qualitative analysis of conflict dynamics identified that in general, although not in the regions where we collected our data, the households' land size increases the likelihood of being 
targeted and victimized by armed groups (2013). As already mentioned, any bias induced by such non-random exposure to violence would likely bias downwards the estimated impact of violence. Moreover, under the assumption of conditional unconfoundedness (Imbens, 2003), we remove the biases that stem from observable pre-violence differences by controlling for these characteristics in matrix $X_{h r}^{t-1}$ in model 1. Finally, following Bellows and Miguel (2009), we conduct a more thorough analysis and regress the number of violent events to which a household was exposed and the victimization score, on a set of ex-ante household characteristics (see Table A3 in the Appendix). The results indicate that the severity of violence was neither based on specific observable characteristics — including pre-violence group membership—nor was it jointly determined by the set of observables.

Naturally, this does not ensure that the severity of the victimization was not based on unobservables - this is, by characteristics that we were unable to measure, but that the armed groups could somehow observe. As mentioned, in our study regions which were newly contested terrain, armed groups relied on indiscriminate violence against civilians as a strategy to obtain territorial supremacy $(\mathrm{CNMH}, 2013) .{ }^{27}$ This is consistent with the logic of violence towards civilians in civil wars (Kalyvas, 2006). Therefore, the severity of violence would be driven by unobservables only if civilians made themselves more conspicuous and put themselves at risk. In a context of widespread violence and civil conflict, it is unlikely that such behaviors would characterize the more hopeless subjects.

To further support the validity of our empirical strategy, we analyze the robustness of the results on the sample of subjects who were victimized en masse,

\footnotetext{
27 By doing so, armed groups spread fear and undermined the popular support for their opponents, which allowed them to control of the movements, activities, preferences, and habits of the population. This constituted, in the words or former combatants, the most effective mechanism to achieve territorial dominance. For this reason, assassinations, mutilations, and massacres, among other manifestations of violent, were often randomly carried out in public spaces; the more vicious the type of violence, the more effective (CNMH, 2013).
} 
with their entire villages in massacres or in the crossfire of combat between illegal armed groups. Therefore, the severity of violence for this subsample is arguably random. ${ }^{28}$ The results reported Appendix Table A5 indicate that the severity of violence brings about a qualitatively robust effect on the perceived prospects of being in extreme poverty. ${ }^{29}$ While this effect is not statistically significant, as the standard error increases considerably due to the smaller sample, the point estimate is stronger in magnitude than what we observed in Table 3-a 5 percentage point increase in the perceived prospects of remaining at the bottom of the ladder. Moreover, we again find a statistically significant effect on the perceived prospects of moving to the top of the ladder. In this case, the point estimate indicates an even stronger 9 percentage points effect on the subjective probability of moving out of poverty.

Together, the results from this subsection suggest that we portray the causal effects of violence based on the statistical and qualitative evidence that indicates that the severity of violence was not driven by observable or unobservable characteristics, and the robustness of the results on a subsample for which the severity of violence was exogenous to pre-violence characteristics.

\section{Alternative Specifications}

In this section, we address three concerns regarding the specification of model 1. First, in model 1 we ignored the pre-violence positions on the ladder of life, which may have been correlated with a host of individual and household skills and could act as a reference point for the victims' perceived prospects of upward

\footnotetext{
28 The characteristics of massive victimizations can be portrayed by the emblematic massacre of the municipality of El Salado in the department of Bolivar, where some subjects in our sample were victimized. In February 2002, over 300 paramilitaries arrived to the municipality head and order the inhabitants to gather in the central plaza. Paramilitaries then selected the victims at random (literally), and tortured and killed them in front of everybody else. Paramilitaries abandoned the town 3 days later, after murdering 70 civilians. All of the survivors migrated soon after (CNMH, 2013).

${ }^{29}$ In this analysis, we do not control for the current position on the ladder, since there is even fewer variation in this characteristic for this subsample.
} 
mobility. In Appendix Table A6, we estimate model 1 including a set of binary indicators of the pre-violence position on the ladder of life. The results indicate that the effect of the severity of violence and the current position on the ladder have a robust and significant effect on victims' perceptions, while the previolence position does not have a significant effect.

Second, the results in Table 3 may hinge on whether the characteristics of each step of the ladder of life accurately represented the living standards for subjects in our sample, and whether subjects with similar living standards placed themselves at the same step. Al alternative is to control for objective measure of the current living standards. For this reason, in Appendix Table A7 we estimate model 1, but now controlling for the measured per capita consumption, which was calculated using a standard consumption module included in the household survey. Again, the results indicate a robust and significant effect of violence on the perceived prospects of being at the bottom step of the ladder of life and of moving to the top step. In addition, the households' per capita consumption portrays the effect of the current step of the ladder of life that we had observed in Table 3: higher levels of consumption have a positive and significant effect on the perceived probability of reaching the top step of the ladder and a negative and significant effect on the perceived probability of being at the second step of the ladder.

Finally, we may be concerned that the subjects did not fully understand the subjective probability elicitation task and that there is significant error in their responses. In Appendix Table A8, we analyze the robustness of our results using the survey-based measures of hopelessness as our dependent variables in model 1. Again, we find a robust effect: a more severe exposure to violence increases the probability that subjects look to the future with hopelessness and despair, and perceptions that it is highly unlikely that the household's socioeconomic circumstances will improve within a year. 


\section{Exploring the Psychological Mechanism}

In this section, we assess whether the effect of violence on victims' perceived prospects of upward mobility is mediated or explained by the psychological consequences of violence. For this purpose, we first document the way in which more severe and recent violence brings about higher symptoms of depression, anxiety and other manifestations of psychological trauma. Then, we exploit the variation in the symptoms of depression to understand how they alter the victims' perceived prospects of upward mobility. Finally, we conduct a mediation analysis to test whether depression explains the effect of violence of victims' perceived prospects of upward mobility. Finding that the reduced form effects of violence are consistent with the psychological theory outlined in Section II is interesting in its own right, and would add further credibility to our core identification strategy.

First, we analyze how the symptoms of psychological trauma vary according to the severity and temporal proximity of violence. For this purpose, we replicate the analysis of Moya (2017) and regress the T-scores for depression, anxiety, or GSI on the standardized number of violent events, the number of years since the episodes of violence, and their interaction. ${ }^{30}$ In conformity with the data in Figure 2 , the results indicate that a more severe and recent exposure to violence produces more severe symptoms of depression and anxiety, and a higher GSI score (see Appendix Table A9). For instance, an increase of one standard deviation in the severity of violence increases the depression and anxiety T-scores by 0.7 and 1 points (see Columns 1 and 3). Likewise, it increases the probability that the symptoms of these two disorders are above the critical threshold by 7 and 5 percentage points, respectively (see Columns 2 and 4). The latter effects account

\footnotetext{
30 In addition, we control for the subjects age and gender to account for well-known differences in the suseptibility to psychological trauma among men and women and across age groups, and include the regional fixed effect. The results are robust if we do not control for these characteristics or for the regional fixed effect.
} 
for an 18-percentage increase relative to the mean, and are consistent with the studies in psychology outlined before on the dose-response relationship between violence and trauma (Mollica et al., 1988; Doctors Without Borders, 2010).

Having established the effects of violence on different psychopathologies, we now address whether psychological trauma is the mechanism through which violence induces hopeless perceived prospects of upward mobility. For this purpose, we estimate a model 2 where we regress $p_{h r}\left(S^{t+1}=k\right)$ on $D_{h r}$, the Tscore for the symptoms of depression, and its quadratic term. Again, we include binary indicators for the current position of the household on the ladder $\mathbf{I}\left(S_{h r}^{t}=\right.$ $j$ ), control for the vectors $X_{h r}^{t}$ and $X_{h r}^{t-1}$ of current individual and pre-violence household covariates, and include a regional fixed effect $\xi_{r}$.

$$
\begin{gathered}
p\left(S_{h r}^{t+1}=k\right)=\beta_{0}+\beta_{1} D_{h r}+\beta_{2} D_{h r}^{2}+\sum_{j=1}^{4} \delta_{j} \mathbf{I}\left(S_{h r}^{t}=j\right)+ \\
\Gamma_{1}{ }^{\prime} X_{i}^{t}+\Gamma_{2}{ }^{\prime} X_{h}^{t-1}+\xi_{r}+\varepsilon_{h r}, \forall k \in[1,4]
\end{gathered}
$$

Panel A of Table 4 reports the results of model 2 and confirms our hypothesis regarding the effect of depression on the victims' perceived prospects of upward mobility. The results indicate that an increase of one point in the depression Tscore raises the perceived probability of being at the bottom two steps of the ladder by 3 and 7 percentage points percentage points, respectively. In addition, it lowers the perceived probability of reaching the top of the ladder by 9 percentage points. These effects are remarkably similar in magnitude to the effects of the severity of violence. The data in the table indicate, in addition, that the effect of the current step of the ladder persists when we control for the extent of psychological trauma. Taken together, these results suggest that the psychological consequences of violence are the mechanism that explains why victims exposed to more severe violence become more hopeless. 
To provide a more thorough analysis of the way in which depression underlies the effect of violence on victims' perceptions, we conduct a mediation analysis following Acharya, Blackwell, and Sen (2016). We estimate the average controlled direct effect of violence- - this is, the causal effect of violence when the effect of depression is accounted for. This approach allows analyzing whether depression is one mechanism through which violence influences victims' perceptions, and whether other mechanisms contribute to this relationship. ${ }^{31}$

The average direct controlled effect of violence is estimated through the following two-stages: In the first stage, we estimate model 1 controlling for the depression T-score and its squared term. Then, we demediate the dependent variable by removing the estimated effect of depression, its squared term, and the current position on the ladder. In the second stage, we estimate the average controlled direct effect of violence by regressing the demediated dependent variable on the severity of violence. Formally, for each future step $k \in[1,4]$, we estimate the following model:

$$
\begin{gathered}
p\left(S_{h r}^{t+1}=k\right)=\gamma_{0}+\gamma_{1} V_{h r}+\gamma_{2} V_{h r}^{2}+\gamma_{3} D_{h r}+\gamma_{4} D_{h r}^{2}+\sum_{j=1}^{4} \delta_{j} \mathbf{I}\left(S_{h r}^{t}=j\right)+ \\
\Gamma_{1}^{\prime} X_{h r}^{t}+\Gamma_{2}^{\prime} X_{h}^{t-1}+\xi_{r}+\varepsilon_{h r} \\
\widehat{p}\left(S^{t+1}=k\right)=\alpha_{0}+\alpha_{1} V_{h}+\alpha_{2} V_{h}^{2}+\Gamma_{2}^{\prime} X_{i}^{t-1}+\xi_{r}+\mu_{i}
\end{gathered}
$$

where $\hat{p}\left(S_{h r}^{t+1}=k\right)=p\left(S_{h r}^{t+1}=k\right)-\hat{\gamma}_{3} D_{h r}+\hat{\gamma}_{4} D_{h r}^{2}-\hat{\delta}_{j}$ is the demediated measure of the victims' perceived prospects of reaching step $k$ of the ladder, and $\mu_{i}$ is the consistent error term estimated through bootstrapping. ${ }^{32}$

\footnotetext{
31 This method provides an alternative to the standard mediation method, where one simultaneously controls for the treatment and mediating variables. As Acharya et al. (2016) discuss, this often leads to biased and inconsistent estimates as a result of M-bias or posttreatment bias.

32 Unbiased and consistent standard errors can be obtained deriving a consistent estimator for the variance of $\widehat{\alpha_{1}}$ for linear models or through bootstrapping. Here, we employ the latter method.
} 


\begin{tabular}{|c|c|c|c|c|}
\hline & $\mathrm{p}($ Step $\mathrm{t}+1=1)$ & $\mathrm{p}($ Step $\mathrm{t}+1=2)$ & $\mathrm{p}($ Step $\mathrm{t}+1=3)$ & $\mathrm{p}($ Step $\mathrm{t}+1=4)$ \\
\hline \multicolumn{5}{|l|}{ A. Reduced Form: Depression T-score } \\
\hline Depression & $\begin{array}{c}0.032 * * \\
{[0.016]}\end{array}$ & $\begin{array}{c}0.072 * * \\
{[0.033]}\end{array}$ & $\begin{array}{l}-0.013 \\
{[0.028]}\end{array}$ & $\begin{array}{c}-0.090^{*} \\
{[0.046]}\end{array}$ \\
\hline Depression $^{2}$ & $\begin{array}{c}-0.000 * * \\
{[0.000]}\end{array}$ & $\begin{array}{c}-0.001 * * \\
{[0.000]}\end{array}$ & $\begin{array}{c}0 \\
{[0.000]}\end{array}$ & $\begin{array}{c}0.001 * * \\
{[0.000]}\end{array}$ \\
\hline Step $t=2$ & $\begin{array}{c}0.000 \\
{[0.000]}\end{array}$ & $\begin{array}{c}0.000 \\
{[0.000]}\end{array}$ & $\begin{array}{c}0.000 \\
{[0.000]}\end{array}$ & $\begin{array}{c}0.000 \\
{[0.000]}\end{array}$ \\
\hline Step $t=3$ & $\begin{array}{c}-0.047 * * * \\
{[0.018]}\end{array}$ & $\begin{array}{c}-0.184 * * * \\
{[0.025]}\end{array}$ & $\begin{array}{c}0.087 * * * \\
{[0.028]}\end{array}$ & $\begin{array}{c}0.144 * * * \\
{[0.037]}\end{array}$ \\
\hline Step $\mathrm{t}=4$ & $\begin{array}{c}-0.068 * * * \\
{[0.024]}\end{array}$ & $\begin{array}{c}-0.266^{* * * *} \\
{[0.035]}\end{array}$ & $\begin{array}{l}-0.029 \\
{[0.044]}\end{array}$ & $\begin{array}{c}0.362 * * * \\
{[0.067]}\end{array}$ \\
\hline Constant & $\begin{array}{l}-0.836 \\
{[0.522]}\end{array}$ & $\begin{array}{r}-1.906^{*} \\
{[1.055]}\end{array}$ & $\begin{array}{c}0.775 \\
{[0.896]}\end{array}$ & $\begin{array}{c}2.966^{* *} \\
{[1.500]}\end{array}$ \\
\hline Hh exante and current controls & Yes & Yes & Yes & Yes \\
\hline $\mathrm{R}^{2}$ & 0.08 & 0.25 & 0.08 & 0.21 \\
\hline Observations & 307 & 307 & 307 & 307 \\
\hline $\begin{array}{l}\text { B. Mediation Analysis: Average Controlle } \\
\text { \# of violent events (standardized) }\end{array}$ & $\begin{array}{c}\text { Direct Effect of } V \\
0.03 \\
{[1.71]}\end{array}$ & $\begin{array}{r}\text { lence } \\
\qquad .04 \\
{[1.43]}\end{array}$ & $\begin{array}{l}-0.02 \\
{[0.78]}\end{array}$ & $\begin{array}{l}-0.06 \\
{[1.83]}\end{array}$ \\
\hline \# of violent events squared (standardized) & $\begin{array}{c}0.00 \\
{[0.27]}\end{array}$ & $\begin{array}{l}-0.01 \\
{[0.74]}\end{array}$ & $\begin{array}{c}0.01 \\
{[1.11]}\end{array}$ & $\begin{array}{c}0.01 \\
{[0.37]}\end{array}$ \\
\hline Hh exante and current controls & Yes & Yes & Yes & Yes \\
\hline $\mathrm{R}^{2}$ & 0.08 & 0.25 & 0.08 & 0.21 \\
\hline Observations & 307 & 307 & 307 & 307 \\
\hline Mean value of dependent variable & 0.067 & 0.267 & 0.337 & 0.329 \\
\hline
\end{tabular}

Notes: Each column reports the results of estimating model 1 on the perceived probabilities of being in each step of the ladder. Panel A reports the estimated coefficients for the severity of symptoms of depression, its quadratic term, and the current position on the ladder. The models include a regional fixed effect and current and ex-ante covariates. Estimated coefficients for these covariates are available upon request. White-robust standard errors are reported in brackets. Panel B reports the average direct controlled effect of violence once the effect of depression and the current position on the ladder are removed. Standard errors are reported in brackets and were obtained through bootstrapping with 1,000 repetitions. *p < 0.10. $* * \mathrm{p}<0.05 . * * * \mathrm{p}<0.01$

Panel B of Table 4 reports the average direct controlled effect of violence that results from the second stage of model 3. The results indicate that we do not reject the null hypothesis. This means that once we account for the effect of depression, violence does not have an additional effect on victims' perceived prospects of upward mobility. Therefore, the results indicate that the effect of 
violence that we observed in Table 3 is driven by the psychological consequences of violence. This result is consistent with the literature in psychology (Sympson, 2000; Yehuda, 2002), and demonstrates that the mechanism through which traumatic experiences of violence can induce hopelessness and perceptions that there are no pathways for real progress.

\section{Violence and Long-Run Perceived Poverty Dynamics}

The implications of the results above can be better understood by simulating the long-run distributions that are associated with the victims' perceived prospects for upward mobility. For this purpose, we use the estimated coefficients from Table 3 , to construct the transition matrices that define the perceived probabilities of transitioning from one step of the ladder to another one over a year, and simulate the associated long-run distribution for different levels of violence. This allows us to illustrate how the experience of more severe violence implies a less favorable long-term distribution.

Define the one period transition matrix $\mathrm{P}$ that defines the perceived probability of transitioning from current ladder step $j$ to ladder step $k$ within a year:

$$
\mathrm{P}=\left[\begin{array}{ccc}
\mathrm{p}_{11} & \cdots & \mathrm{p}_{14} \\
\vdots & \ddots & \vdots \\
\mathrm{p}_{41} & \cdots & \mathrm{p}_{44}
\end{array}\right],
$$

where element $\mathrm{p}_{\mathrm{jk}}$ is the perceived probability that an individual at step $j$ in period $t$ will be at step $k$ in period $t+1$. Note that this structure can accommodate a wide variety of probability processes ranging from convergent to divergent or processes. In general, perceived prospects for downward mobility would be signaled by the lower triangle.

Furthermore, let $\lambda_{t}$ be the $4 \times 1$ vector that denotes the population distribution across the 4 steps of the ladder of life in period $t$. Given P, the expected distribution of the population in period $t+1$ will be $\lambda_{t+1}=\mathrm{P}^{\prime} \lambda_{\mathrm{t}}$. If we further 
assume that the transition process is governed by a stable Markovian process in which transition probabilities only depend on the current position, then $\lambda_{\mathrm{t}+2}=\mathrm{P}^{\prime}\left[\mathrm{P}^{\prime} \lambda_{\mathrm{t}}\right]$. For a well-defined probability matrix, the population distribution will converge in the long-run to the stable equilibrium distribution given by the eigenvector $\lambda_{\mathrm{e}}=\mathrm{P}^{\prime} \lambda_{\mathrm{e}}$.

Note that following model 1 , in the previous section we estimated a set of equations for the perceived probabilities associated with each future step $k$ on the ladder of life for subjects currently at each step $j$. Hence, each equation in model 1 provides the information necessary to construct the corresponding column of the transition matrix. To calculate the element $\mathrm{p}_{\mathrm{jk}}$, we first estimate the equation for the probability of being at step $k$ in the following period, $p\left(S t e p^{t+1}=k\right)$. Then, we set the individual and household controls at their mean values and calculate the predicted probability for step $k$, conditional on the current step of the ladder $j$, and across different levels of violence $v$. Formally, the predicted conditional probability $\hat{\mathrm{p}}_{\mathrm{jk}}$, for a subject at step $j$, who was exposed to given level of violence $v$, will be given by:

$$
\hat{p}_{j k}(v)=\hat{\gamma}_{0}+\hat{\gamma}_{2} v+\hat{\gamma}_{2} v^{2}+\widehat{\delta}_{J}+\hat{\Gamma}_{1} \bar{X}_{i}^{t}+\hat{\Gamma}_{2}^{\prime} X_{h}^{t-1}+\hat{\xi}_{r}
$$

Table 5 displays the simulated transition matrices and the associated population long-run distributions when violence is set at the values for the $10^{\text {th }}$ and $75^{\text {th }}$ percentiles-a one standard deviation increase. ${ }^{33}$ The effect of violence on the perceived prospects for upward mobility can be observed by noting that the perceived probabilities in the lower triangle of the transition matrix are higher for subjects exposed to more severe violence than for those exposed to less violence. Moreover, the associated long-run distributions reveal that if an average victim were to experience an increase in the severity of violence from the $10^{\text {th }}$ to the $75^{\text {th }}$

\footnotetext{
33 Table A10 in the Appendix reports transition matrix and long-run population distributions for different percentiles of the distributions of the severity of violence.
} 
percentile, the perceived likelihood of ending up in extreme poverty would increase by 8 percentage points. This entails a sizeable 160 percent effect and further highlights how the exposure to more severe violence leads victims' perceived prospects of upward mobility to become increasingly hopeless. ${ }^{34}$

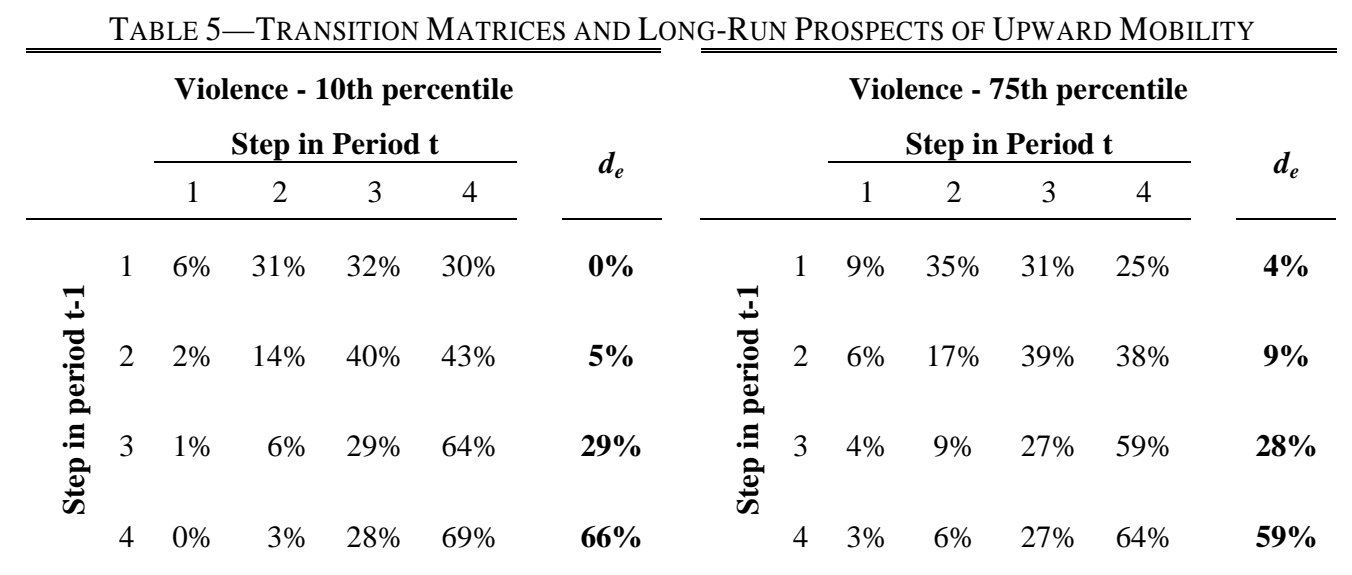

Notes: Transition matrices that define the perceived probabilities of transitioning from one step of the ladder to another one over some time period, and associated long-run distributions for two levels of violence: at the values of the $10^{\text {th }}$ and $75^{\text {th }}$ percentiles. Each element of the transition matrix is based on the estimation of model 4.

To further illustrate this point, Figure 4 plots the evolution of the extreme poverty headcount - this is, the percentage of victimized households who are in extreme poverty at different moments of time based on transition matrices for the two levels of violence specified above. The figure illustrates how the extreme poverty headcount falls relatively quickly, in conformity with the victims' perceptions outlined in Figure 3. However, the figure also illustrates how the transitional dynamics diverge rather quickly signaling a large increment in the number of victims that expect to be in extreme poverty because of the exposure to more severe violence and the associated psychological consequences.

Of course, these long-run estimates are subject to the proviso that the actual socioeconomic dynamics can be characterized by a Markov process, and that the

\footnotetext{
34 Likewise, a one standard deviation increase in the severity of violence lowers the likelihood of reaching the top of the ladder by 8 percentage points; a 13 percent difference.
} 
transitional matrices remained unaltered over time even as the socioeconomic circumstances of the household improve. Yet, we argue that this a good characterization of victims' perceived prospects since the results from the previous section indicate that the effect of violence persists over time and is independent of the levels of wellbeing. Therefore, the results above sharply illustrate how violence operates as an additional force that dampens victims' perceived prospects of future economic advance and can bring about a behavioral poverty trap. This speaks to the work of Sen (1999), who suggested that internal constraints can be more binding than the more noticeable economic constraints, and can create a behavioral poverty trap.

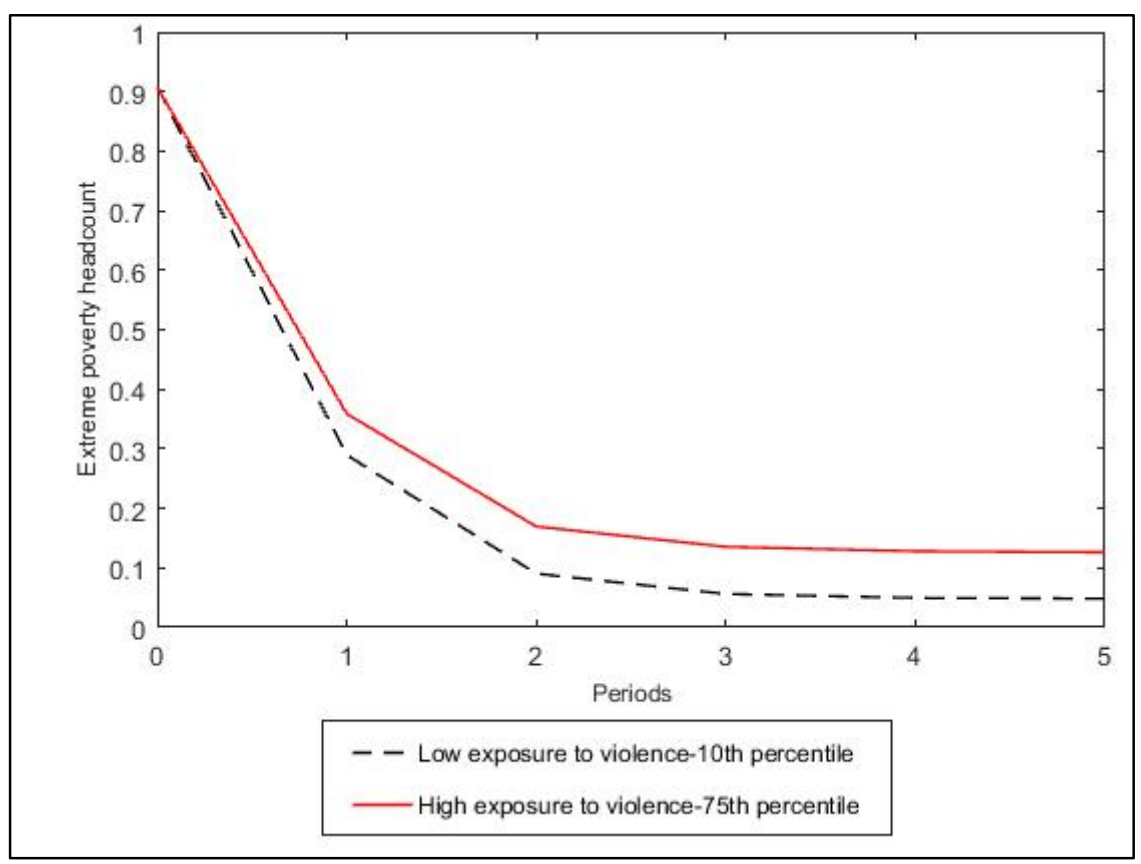

Figure 4. Simulated Extreme Poverty HeadCount

Notes: Simulated evolution of the extreme poverty headcount based on the transition matrices depicted in Table 5. 


\section{Discussion and Policy Implications}

In this paper, we have analyzed if the exposure to violence more severe violence leads victims' perceived prospects of upward mobility to become increasingly hopeless. We focused on a group of victims of violence in Colombia and collected data on their exposure to violence, symptoms of psychological trauma, and perceived prospects of upward mobility. Our results indicate that the exposure to more severe violence dampens the perceived prospects of upward mobility. Importantly, this effect persists even after we account for the effect of current levels of wellbeing, consumption, education, and asset losses. The effect of violence therefore signals to the existence of internal constraints, that go beyond the "true" obstacles or external constraints imposed by violence and forced displacement. In fact, we demonstrate that the psychological consequences of violence, and the severity of symptoms of depression in particular, are the mechanism through which violence begets hopelessness.

Taken together, our results echo the testimony of the victim at the beginning of this paper, which portrays how violence restricted her ability to hope for a better future. More generally, our findings are consistent with those of psychological studies that show that the experience of trauma triggers depressive explanatory styles and can induce learned helplessness. Violence can therefore hinder the victims' willingness to try to make the best out of what they have, and contribute to the persistence of poverty. Precisely, the simulation analysis of the previous section, highlights that the psychological consequences of violence can become more binding than the more discernible external constraints and create a behavioral poverty trap.

One of the limitations of our analysis is that we are unable to observe whether the perceived prospects of upward mobility affect behavior and actual socioeconomic transitions. However, we believe that this is possible by drawing 
upon the work of Cuartas and Moya (2016), who followed our methodological approach to collect data on perceived prospects of upward mobility from a subsample of the Colombian Longitudinal Survey (ELCA for its Spanish acronym). Their analysis indicates that the perceived prospects of upward mobility, which were measured in 2011, have a strong and significant impact on households' economic trajectories between 2011 and 2013. Moreover, their results indicate that the effect persists when they control for a host of observable characteristics related to the households' physical, human, and social assets. Hence, their results also point to the role of internal constraints in shaping the perceived prospects and the actual patterns of socioeconomic mobility.

Our paper has important policy implications and suggests reconsidering the strategies to assist the victims of violence and other negative shocks. In the case of Colombia, for example, the Government has set a progressive set of laws and implemented comprehensive programs to assist the victims since 1997. These include humanitarian and conditional cash transfers and access to subsidized education and health, which are thought to provide a safety net to minimize the negative consequences of violence and forced displacement. In addition, the Government has laid out a strategy to promote the socioeconomic recovery of victims through asset and land transfers, job training programs, and indemnities up to US $\$ 8,000$, among others. Unfortunately, the psychological consequences of violence have been largely neglected and mental health programs are scarce and poorly funded. According to data of the Colombian Ministry of Health, between 2013 and 2016, less than 4 percent of the victims in the country have received psychological assistance, while less than $1 \%$ of the funds allocated by the Government for the victims' recovery are invested in mental health programs. This is unfortunate since our results suggest that the psychological consequences of violence set seeds for persistent poverty. 
To conclude, we conduct a simple thought experiment to illustrate how psychological trauma may hinder the effectiveness of other, more traditional types of programs. For this purpose, we return to the simulation analysis of the previous section and assess how the long-run poverty dynamics depicted in Figure 4 would change if we provided an asset transfer to the victims exposed to more severe violence, but without implementing any psychological assistance that could alleviate the internal constraints. In particular, we simulate the poverty headcount across time using the initial population distribution and the transition matrices depicted in Table 5. After period 1, we provide an asset transfer to the victims at the $75^{\text {th }}$ percentile of the distribution of the severity of violence that pushes them one step upwards in the ladder of life.

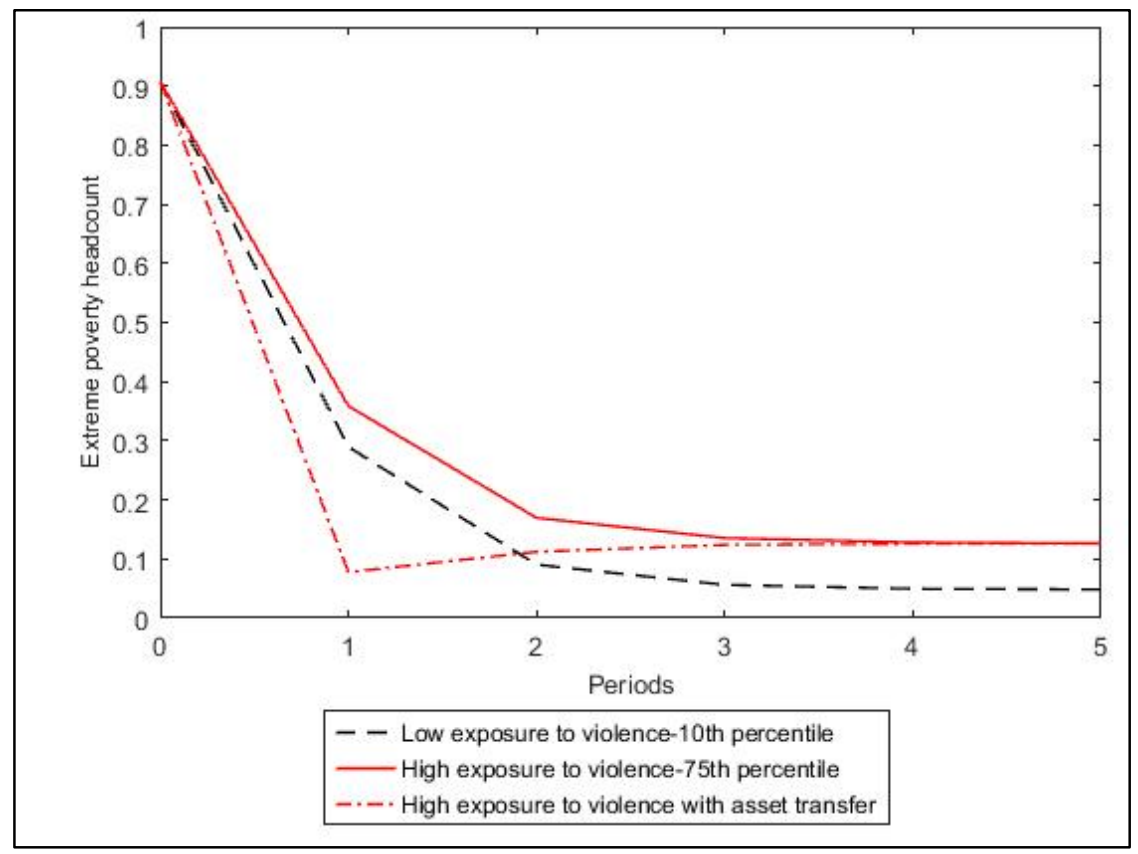

Figure 5. Simulated EXTREME POVERTY HEAdCOUNT UNDER A STANDARD ASSET TRANSFER Notes: Simulated evolution of the extreme poverty headcount based on the transition matrices depicted in Table 5, and an asset transfer for the victims exposed to more severe violence that pushes them one step upwards in the ladder of life in period 1.

Figure 5 illustrates the evolution of the extreme poverty headcount for the victims exposed to low violence, and those exposed to more severe violence with 
and without the asset transfer. The figure indicates that in the medium run, the asset transfer lowers the extreme poverty headcount for the victims exposed to more severe violence, and would alleviate material and external constraints. Nevertheless, the figure also indicates that in the long run, the extreme poverty head count for victims exposed to more severe violence converges to the previous level without the asset transfer. The dynamics in Figure 5 therefore indicate that even if victims live a world of convergent socioeconomic mobility, the psychological consequences of violence can render standard interventions ineffective and alter the long run distribution of well-being. Our paper thus provides additional justification for a better understanding the psychological consequences of violence and how they influence poverty dynamics, and for designing and implementing psychological programs for victims of violence. 


\section{REFERENCES}

Acharya A., Blackwell, M., and Sen, M. (2016) Explaining causal findings without bias: Detecting and assessing direct effects. American Political Science Review, 110(3), 512-529 doi:10.1017/S0003055416000216

Allousch, M. (2017). Income, Psychological Well-being, and the Dynamics of Poverty: Evidence from South Africa, working paper, University of California, Davis.

Appadurai, A. (2004). The capacity to aspire: Culture and the terms of recognition. In V. Rao, and M. Walton (Eds.), Culture and public action (pp. 59-84). Stanford, CA: Stanford University Press.

Barrett, C., M.R. Carter and J-P Chavas (forthcoming). The economics of poverty traps. In C. Barrett, M.R. Carter and J-P Chavas (Eds.). The economics of poverty traps (pp. xx-yy). Chicago: University of Chicago Press.

Bernard, T., Dercon, S., Orkin, K., and Taffesse, A.S. (2015). Will Video Kill the Radio Star? Assessing the Potential of Targeted Exposure to Role Models through Video. The World Bank Economic Review, 29(1), 226-237. doi:10.1093/wber/lhv014

Bauer, M., Cassar, A., Chytilova, J., and Henrich, J. (2014). War's enduring effects on the development of egalitarian motivations and in-group biases. Psychological Science, 25(1), 47-57. doi:10.1177/0956797613493444.

Bellows, J., and Miguel, E. (2009). War and local collective action in Sierra Leone. Journal of Public Economics, 93(11-12), 1144-1157. doi:10.1016/j.jpubeco.2009.07.012.

Blattman, C. (2009). From violence to voting: War and political participation in Uganda. American Political Science Review, 103(2), 231-247. doi:10.1017/S0003055409090212.

Briere, J.and Spinazzola, J. (2005). Phenomenology and psychological assessment of complex posttraumatic states. Journal of Traumatic Stress, 18, 401-412. doi:10.1002/jts.20048

Callen, M., Isaqzadeh, M., Long, J. D., and Sprenger, C. (2014). Violence and risk preference: Experimental evidence from Afghanistan. American Economic Review, 104(1), 123-148. doi:10.1257/aer.104.1.123.

Carter, M.R., and May, J. (2001). One Kind of Freedom: Poverty Dynamics in Post-apartheid South Africa. World Development, 29(12), 1987-2006. doi: 10.1016/S0305-750X(01)00089-4

Carter, M. R., and Barrett, C. B. (2006). The Economics of Poverty Traps and Persistent Poverty: An AssetBased Approach. Journal of Development Studies, 42(2), pp. 178-199. doi:10.1080/00220380500405261

Carter, M. R., Little, P.D., Mogues, T., and Negatu, W. (2007). Poverty Traps and Natural Disasters in Ethiopia and Honduras. World Development, 35(5), 835-856. doi:10.1016/j.worlddev.2006.09.010

Cassar, A., Grosjean, P., and Whitt, S. (2014). Social preferences of ex-combatants: Survey and experimental evidence from postwar Tajikistan. In K. Wärneryd (Ed.), The economics of conflict: Theory and empirical evidence (pp. 231-262). Cambridge MA: MIT Press. doi:10.7551/mitpress/9780262026895.001.0001.

Cassar, A., Grosjean, P., and Whitt, S. (2013). Legacies of violence: Trust and market development. Journal 
of Economic Growth, 18(3), 285-318. doi:

Cassar, A., and Wyddick, B. (2017) What Raises Achievement among the Poor? Experimentally testing Goals, Incentives, and Support Groups in Medellin, Colombia. University of San Francisco. Unpublished Manuscript.

Casullo, M. M. (2004). El inventario de síntomas SCL-90-R de L. Derogatis. Adaptación UBA.

Centro Nacional de Memoria Histórica (CNMH). (2013). ¡Basta ya!: Colombia: Memorias de guerra y dignidad. Retrieved from http://www.centrodememoriahistorica.gov.co/micrositios/informeGeneral/descargas.html.

Chiapa, C., Prina, S., and Parker, A. (2016). The Effects of Financial Inclusion on Children's Schooling, and Parental Aspirations and Expectations. Journal of International Development, 28(5), 683-696.

Cuartas, J., and Moya, A. (2016). Self-Fulfilling Prophecies: Expectations, Psychological Distress, and Social Mobility in Colombia. Working Paper.

Dalton, P. S., Ghosal, S., and Mani, A. (2016). Poverty and aspirations failure. The Economic Journal, 126 (590) 165-188. doi:10.1111/ecoj.12210.

De Quidt, J. and H, Haushofer (forthcoming). Depression through the Lens of Economics: A Research Agenda. In C. Barrett, M.R. Carter and J-P Chavas (Eds.). The economics of poverty traps (pp. xx-yy). Chicago: University of Chicago Press.

Jonathan de Quidt $\dagger$ Johannes Haushofer

Doctors Without Borders. (2006). Living with fear: The cycle of violence in Colombia. Retrieved from https://issuu.com/msf_australia/docs/colombia_living_in_fear_0406.

Duflo, E. (2013). Hope, aspirations, and the design of the fight against poverty. Stanford, CA: Stanford University Center for Ethics in Society, [Lecture]. 2 October.

Glewee, P., Ross, P.H., \& Wydick, B. (2017) Developing Hope Among Impoverished Children: Using Child

Self-Portraits to Measure Poverty Program Impacts. Journal of Human Resources, forthcoming doi: 10.3368/jhr.53.2.0816-8112R1

Garber, J., and Seligman, M.E.P. (1980). Human Helplessness: Theory and Applications. New York: Academic Press.

Human Rights Watch. (2010). World report 2010: Events of 2009. Retrieved from http://www.hrw.org/sites/default/files/reports/wr2010.pdf.

Ibáñez, A. M., and Moya, A. (2010a). Vulnerability of victims of civil conflicts: Empirical evidence for the displaced population in Colombia. World Development, 38(4), 647-663. doi:10.1016/j.worlddev.2009.11.015.

Ibáñez, A. M., and Moya, A. (2010b). Do conflicts create poverty traps? Asset losses and recovery for displaced households in Colombia. In R. Di Tella, S. Edwards, and E. Schargrodsky (Eds.), The economics of crime: Lessons for and from Latin America (pp. 137-172). Chicago: University of Chicago Press. doi: 10.1093/acprof:oso/9780199378296.001.0001

Imbens, G. (2003). Sensitivity to Exogeneity Assumptions in Program Evaluation. American Economic 
Review 93(2), 126-132. doi:10.1257/000282803321946921

Instituto de Estudios para el Desarrollo y la Paz (Indepaz). (2011). Seventh report of presence of narcoparamilitary groups in 2011. Retrieved from www.indepaz.org.co/wpcontent/uploads/2012/02/S\%C3\%A9ptimo-informe-versi\%C3\%B3n-ing1\%C3\%A9s-of-

Narcoparamilitary-Groups-in-2011.pdf.

Jensen, R., and Oster, E. (2009). The Power of TV: Cable Television and Women's Status in India. The Quarterly Journal of Economics, 124(3), 1057-1094. doi:10.1162/qjec.2009.124.3.1057.

Lipman, A., and Havens, E. (1965). The Colombian Violencia: An Ex Post Facto Experiment. Social Forces, 44(2), 238-245. doi:10.1093/sf/44.2.238

Lybbert, T.J., and Wydick, B. (forthcoming). Hope as aspirations, agency, and pathways: poverty dynamics and microfinance in Oaxaca, Mexico. In Barrett, C., M.R., Carter, and J.P. Chavas (Eds.). The Economics of Poverty Traps. University of Chicago Press. (forthcoming).

Kalyvas, S. (2006). The logic of violence in civil war. Cambridge studies in comparative politics. New York: Cambridge University Press. doi:10.1086/522394

Kessler, R. C, Sonnega, A., Bromet, E., Hughes, M., and Nelson, C. B. (1995). Posttraumatic stress disorder in the national comorbidity survey. Archives of General Psychiatry, 52(12), 1048-1060. doi:10.1001/archpsyc.1995.03950240066012.

Kosec, K., and Hyunjung C. (2017). Aspirations and the role of social protection: evidence from a natural disaster in rural Pakistan. World Development, 97, 49-66. doi:10.1016/j.worlddev.2017.03.039

Krishna, A. (2001). Moving from the Stock of Social Capital to the Flow of Benefits: The Role of Agency. World Development, 29(6), 925-243. doi:/10.1016/S0305-750X(01)00020-1

Krishna, A. (2004). Escaping Poverty and Becoming Poor: Who Gains, Who Loses, and Why? World Development, 32(1), 121-136. doi:10.1016/j.worlddev.2003.08.002

Krishna, A. (2006). Pathways out of and into poverty in 36 villages of Andhra Pradesh, India. World Development, 34(2), 271-288. doi.org/10.1016/j.worlddev.2005.08.003

Lipman, A., and Havens, A.E. (1965). The Colombian violencia: An ex post facto experiment. Social Forces, 44(2). 238-245. doi.org/10.1093/sf/44.2.238

Macours, K., and Vakis, R. (2014). Changing households' investment behaviors through social interactions with local leaders: evidence from a randomized transfer programme. Economic Journal, 124, 607-633. doi:10.1111/ecoj.12145

Matijasevic, M.T, Velásquez, L., Villada, C., and Ramírez, M. (2007). Moving Out of Poverty: understanding freedom, growth, and democracy from the bottom-up. Colombia National Synthesis Report. Retrieved from $\quad$ http://siteresources.worldbank.org/INTMOVOUTPOV/Resources/21042151187710751691/Colombia_synthesis.pdf

Mollica, R. F., McInnes, K., Poole, C., and Tor, S. (1998). Dose-effect relationships of trauma to symptoms of depression and post-traumatic stress disorder among Cambodian survivors of mass violence. The British Journal of Psychiatry, 173(6), 482-488. doi: 10.1192/bjp.173.6.482 
Moya, A. (2018). Violence, psychological trauma, and risk attitudes: Evidence from victims of violence in Colombia. Journal of Development Economics, 131, 15-27. doi.org/10.1016/j.jdeveco.2017.11.001

Narayan, D., Pritchett, L., and Kapoor, S. (2009). Moving Out of Poverty: Success from the Bottom Up. Moving Out of Poverty, Volume 2. Washington, DC: World Bank and Palgrave Macmillan. https://openknowledge.worldbank.org/handle/10986/11838

Narayan, D., and Petesch, P. (2010). Moving Out of Poverty: Rising from the Ashes of Conflict. Moving Out of Poverty, Volume 4. Washington, DC: World Bank and Palgrave Macmillan. https://openknowledge.worldbank.org/handle/10986/11837

National Victims Unit. (n.d.). National victims' unit official registry. Retrieved from http://rni.unidadvictimas.gov.co.

Ray, D. (2006). Aspirations, poverty, and economic change. In A. Banerjee, R. Benabou, and D. Mookherjee (Eds.), Understanding poverty (pp. 409-443). Oxford, UK: Oxford University Press.

Richards, A., Ospina-Duque, J., Barrera-Valencia, M., Escobar-Rincón, J., Ardila-Gutiérrez, M., Metzler, T., and Marmar, C. (2011). Posttraumatic stress disorder, anxiety and depression symptoms, and psychosocial treatment needs in Colombians internally displaced by armed conflict: A mixed-method evaluation. Psychological Trauma: Theory, Research, Practice, and Policy, 3(4), 384-393. doi:10.1037/a0022257.

Rotter, J. B. (1966). Generalized expectancies for internal versus external control of reinforcement. Psychological Monographs: General and Applied, 80(1), 1-28. doi:10.1037/h0092976

Seligman, M.E.P. (1975). Helplessness: On Depression, Development and, Death. San Francisco: W.H. Freeman

Sen, A. (1999). Development as Freedom. Oxford University Press.

Shultz, J. M., Garfin, D. R., Espinel, Z., Araya, R., Oquendo, M. A., Wainberg, M. L., ... Neria, Y. (2014). Internally displaced "victims of armed conflict" in Colombia: The trajectory and trauma signature of forced migration. Current Psychiatry Reports, 16(10), 475. doi:10.1007/s11920-014-0475-7.

United Nations High Commissioner for Refugees (UNHCR). (2016). Population statistics. Retrieved from http://popstats.unhcr.org/en/overview.

Voors, M. J., Nillesen, E. E., Verwimp, P., Bulte, E. H., Lensink, R., and Van Soest, D. P. (2012). Violent conflict and behavior: A field experiment in Burundi. American Economic Review, 102(2), 941-964. doi:10.1257/aer.102.2.941.

Yehuda, R. (2002). Post-traumatic stress disorder. New England Journal of Medicine, 346, 108-114. doi:10.1056/NEJMra012941. 